\title{
Multi-scale Observations of Atmospheric Moisture Variability in relation to Heavy Precipitating Systems in the north-western Mediterranean during HyMeX IOP12
}

\begin{tabular}{|c|c|}
\hline Journal: & QJRMS \\
\hline Manuscript ID & QJ-17-0325.R2 \\
\hline Wiley - Manuscript type: & Research Article \\
\hline Date Submitted by the Author: & 12-Jul-2018 \\
\hline Complete List of Authors: & $\begin{array}{l}\text { Khodayar, Samiro; Institute for Meteorology and Climate Research, } \\
\text { Karlsruhe Institute of Technology (KIT), } \\
\text { Czajka, Beata; Institute for Meteorology and Climate Research, Karlsruhe } \\
\text { Institute of Technology (KIT) } \\
\text { Caldas-Alvarez, Alberto; Institute for Meteorology and Climate Research, } \\
\text { Karlsruhe Institute of Technology (KIT) } \\
\text { Helgert, Sebastian; Institute for Meteorology and Climate Research, } \\
\text { Karlsruhe Institute of Technology (KIT) } \\
\text { Flamant, Cyrille; Université Pierre et Marie Curie and CNRS, LATMOS } \\
\text { Di Girolamo, Paolo; Università degli Studi della Basilicata, Dipartimento di } \\
\text { Ingegneria e Fisica dell'Ambiente - DIFA } \\
\text { Bock, Olivier; LAREG, Institut National de I'Information Géographique et } \\
\text { Forestière (IGN), Univ. Paris Diderot } \\
\text { Chazette, Patrick; CEA, LSCE }\end{array}$ \\
\hline Keywords: & $\begin{array}{l}\text { HyMeX, Heavy Precipitation Systems, Convection }<3 \text {. Physical } \\
\text { phenomenon, multi-scale water vapour variability, Observations }<1 \text {. Tools } \\
\text { and methods, moisture origin, HyMeX, Heavy Precipitation System, } \\
\text { convection, multi-scale water vapour variability, observations }\end{array}$ \\
\hline Country Keywords: & Germany \\
\hline
\end{tabular}




\section{Multi-scale Observations of Moisture Variability in relation to Heavy Precipitating Systems in the north-western Mediterranean during HyMeX IOP12}

${ }^{* 1}$ S. Khodayar, ${ }^{1}$ B. Czajka, ${ }^{1}$ A. Caldas-Alvarez, ${ }^{1}$ S. Helgert, ${ }^{2}$ C. Flamant, ${ }^{3}$ P. Di Girolamo, ${ }^{4}$ O. Bock, ${ }^{5}$ P. Chazette

${ }^{1}$ Institute of Meteorology and Climate Research (IMK-TRO), Karlsruhe Institute of Technology (KIT), Karlsruhe, Germany

${ }^{2}$ LATMOS/IPSL, UPMC Univ. Paris 06 Sorbonne Universités, UVSQ, CNRS, Paris, France

${ }^{3}$ Scuola di Ingegneria, Università della Basilicata, Via dell'Ateneo Lucano n. 10, 85100 Potenza, Italy.

${ }^{4}$ IGN LAREG, Univ. Paris Diderot, Sorbonne Paris Cité, 5 rue Thomas Mann, 75205 Paris CEDEX 13, France

${ }^{5}$ Laboratoire des Sciences du Climat et de l'Environnement, CEA-CNRS-UVSQ, Gif-surYvette, France 
This article investigates the spatio-temporal variability of atmospheric water vapour across scales in relationship with the occurrence of heavy precipitation systems in the north-western Mediterranean. Synergies between different instruments, Global Positioning System (GPS) stations, radiosondes, airborne and ground-based Lidars and space-borne observations from the Moderate Resolution Imaging Spectroradiometer (MODIS), among others, are used. Highresolution convection permitting simulations complement the observational network.

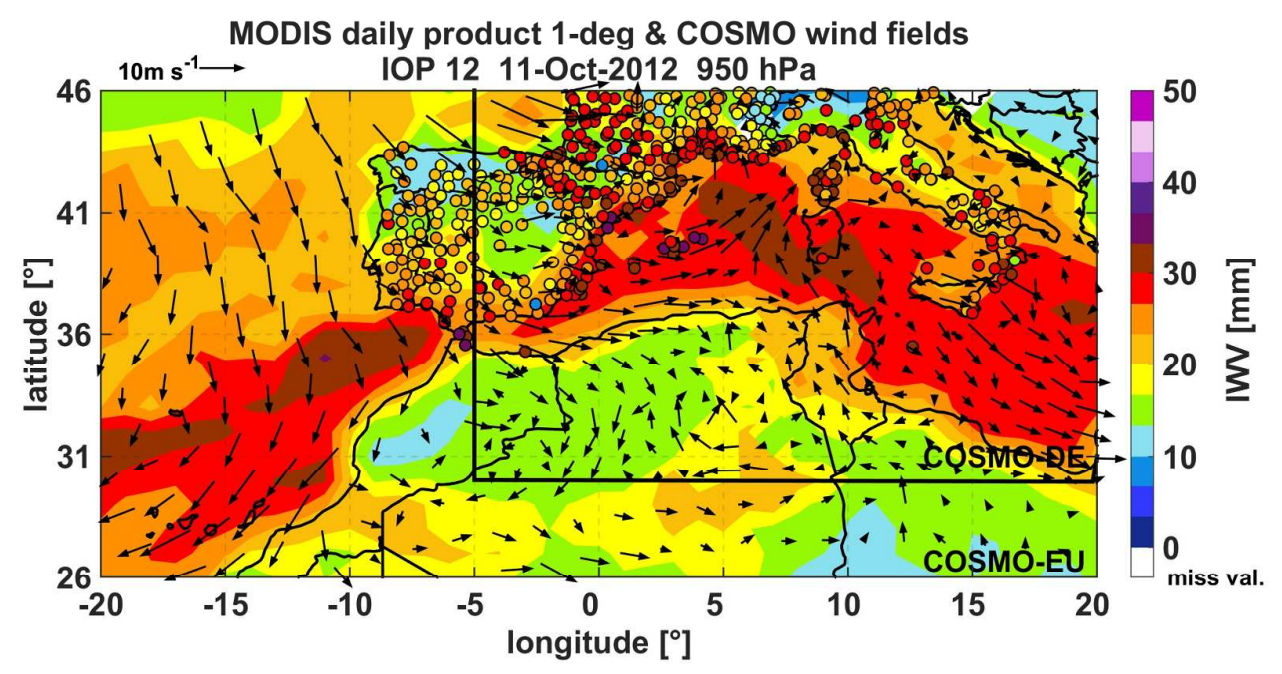

Daily mean spatial distribution of total column Integrated Water Vapour (IWV) from MODIS (background) and GPS (circles) observations. Simulated COSMO-7 km and COSMO-2.8km $950 \mathrm{hPa}$ winds at $1200 \mathrm{UTC}$ are superimposed. 
Multi-scale Observations of Atmospheric Moisture Variability in relation to Heavy Precipitating Systems in the north-western Mediterranean during HyMeX IOP12

${ }^{1}$ S. Khodayar, ${ }^{1}$ B. Czajka, ${ }^{1}$ A. Caldas-Alvarez, ${ }^{1}$ S. Helgert, ${ }^{2}$ C. Flamant, ${ }^{3}$ P. Di Girolamo, ${ }^{4}$ O. Bock, ${ }^{5} \mathrm{P}$. Chazette

${ }^{1}$ Institute of Meteorology and Climate Research (IMK-TRO), Karlsruhe Institute of Technology (KIT), Karlsruhe, Germany

${ }^{2}$ LATMOS/IPSL, UPMC Univ. Paris 06 Sorbonne Universités, UVSQ, CNRS, Paris, France

${ }^{3}$ Scuola di Ingegneria, Università della Basilicata, Via dell'Ateneo Lucano n. 10, 85100 Potenza, Italy.

${ }^{4}$ IGN LAREG, Univ. Paris Diderot, Sorbonne Paris Cité, 5 rue Thomas Mann, 75205 Paris CEDEX 13, France

${ }^{5}$ Laboratoire des Sciences du Climat et de l'Environnement, CEA-CNRS-UVSQ, Gif-surYvette, France

Submitted to QJRMS

* Corresponding author. E-mail address: samiro.khodayar@kit.edu (S. Khodayar) Institute for Meteorology and Climate Research, Karlsruhe Institute of Technology (KIT), Postfach 3640, 76021 Karlsruhe, Germany 


\begin{abstract}
1 The deployment of special instrumentation for the Hydrological Cycle in the Mediterranean

2 Experiment $(\mathrm{HyMeX})$ provides a valuable opportunity to investigate the spatio-temporal

3 variability of atmospheric water vapour across scales in relationship with the occurrence of

4 Heavy Precipitation Systems (HPSs) in the north-western Mediterranean (WMed) during the

5 Intensive Observation Period (IOP12), which is the focus of this investigation. High-

6 resolution convective permitting COSMO simulations complement the observational network

7 and allow the calculation of online trajectories.
\end{abstract}

8 In addition to the presence of a favourable large-scale situation and low-level convergence, 9 atmospheric moisture changes resulting in conditionally unstable air are identified as responsible for convective initiation (CI). All HPSs within the north-WMed form in periods/areas of maximum Integrated Water Vapour (IWV; 35-45 $\mathrm{kg} \mathrm{m}^{-2}$ ) after an increase of about $10-20 \mathrm{~kg} \mathrm{~m}^{-2}$. The most intense events receive moisture from different sources simultaneously and show a sudden increase of about $10 \mathrm{~kg} \mathrm{~m}^{-2}$ between $6-12 \mathrm{~h}$ prior to the event, whereas in the less intense events the increase is larger, about $20 \mathrm{~kg} \mathrm{~m}^{-2}$, over a period of at least $24 \mathrm{~h}-36 \mathrm{~h}$. Changes in the lower $(\sim 900 \mathrm{hPa})$ and mid-troposphere $(\sim 700 \mathrm{hPa})$ control the evolution of the atmospheric moisture and the instability increase prior to CI. Spatial inhomogeneities in the lower boundary layer determine the timing and location of deep convection, whereas enhanced moisture in the mid-troposphere favours intensification. Moister and deeper boundary layers, with updraughts reaching up to $2 \mathrm{~km}$ are identified in those pre-convective environments leading to HPS, whereas dry, shallow boundary layers are found everywhere else. The build-up time and vertical distribution of the moisture changes are found to be crucial for the evolution and severity of the HPSs rather than the amount of total column atmospheric moisture. 
5

7

8

9

10

11

12

13

14

15

16

17

25 Key Words: HyMeX, Heavy Precipitation System, convection, multi-scale water vapour 26 variability, observations

27 
44

45

46

47

\section{Introduction}

Every year, the Mediterranean region is affected by high impact weather mainly in the form of Heavy Precipitation Systems (HPSs). These come often in the form of severe storms bringing, in addition to heavy precipitation and flooding, strong wind gusts, intense lightning, large hail and even tornadoes. Most of the HPSs with the accompanying flash floods occur between September and November and are caused mainly by Mesoscale Convective Systems (MCSs; Riosalido 1990).

Although the large-scale processes governing the occurrence of convection producing HPSs in the western Mediterranean (WMed) have long been studied and are generally well understood (e.g. Nuissier et al. 2008), there still are open questions concerning the role of enhancing factors affecting the initiation, the development, the type or the severity of convective storms. Among these, atmospheric water vapour is crucial for the occurrence of deep convection.

It is well known that besides a triggering mechanism, large-scale lifting and/or low level convergence allowing the release of the potential energy, small convective inhibition, and an conditionally unstable atmosphere, the main ingredient required for the occurrence of deep convection is a moist atmosphere (Doswell et al. 1996). Particularly relevant is the presence of sufficient moisture in the low- and mid-trosposhere (e.g. Khodayar et al 2010, 2013). The availability of moisture for precipitation is controlled by a number of processes including mixing on small scales, convective processes on different scales, and advection on the mesoscale and large-scale.

Former studies (e.g. Nuissier et al. 2011) pointed out that HPSs in the WMed often occur under the influence of a synoptic pattern that is quasi-stationary in time and favours a steady low-level moist flow towards the coast. This transport of moisture provides the large amounts of water vapour needed to feed the precipitating systems producing huge quantities of 
precipitation recorded during these events. Modelling studies in the last years also suggest that the main moisture sources for HPSs in the north-WMed are evaporation from North Africa, the Mediterranean and the Atlantic (e.g. Winschall et al. 2012; Duffourg and Ducrocq 2013; Ramos et al. 2016). The time scale of the moisture transport was assessed to be about 2 days for local sources, and 2 to 5 for contributions from the Tropics. Few observational investigations have been conducted to confirm these results (e.g. Chazette et al. 2016a; Lee et al. 2016). Furthermore, humidity shows large spatial and temporal variability on the mesoscale (Crook 1996; Lauscaux et al. 2004; Weckwerth et al. 1996, 2000; Khodayar et al. 2010, 2013, 2016a). The small-scale variations of humidity can directly influence convective initiation (CI), as well as its further development potential (Sherwood et al. 2010). Moisture variations of about $1 \mathrm{~g} \mathrm{~kg}^{-1}$ in the Planetary Boundary Layer (PBL) can make the difference between no initiation and intense convection (Crook 1996). Weckwerth et al. (1996) showed that this magnitude of variability occurs regularly in the PBL on distances of a few kilometres only.

The combination of the various processes and scales discussed above results in a high variability in both space and time, whose exact knowledge is essential for both Numerical Weather Prediction (NWP; e.g. Weckwerth et al. 1999) and climate modelling (e.g. Bony et al. 2006). Advances have been achieved in the last years concerning convective processes modelling; however, the scarcity of water vapour observations at the mesoscale and smaller scales still hampers progress. The origin, pathways and time scales of transport of the large amounts of moisture necessary for HPSs in the WMed are still open questions. Additionally, our understanding of the distribution, and variability of water vapour in relationship with convection is still far from being complete.

Due to its importance, the characterization of water vapour has been a crucial aspect in the first of the two field campaigns of the Hydrological cycle in the Mediterranean Experiment (HyMeX; Drobinski et al. 2014). The Special Observation Period (SOP1; Ducrocq et al. 
2014) provided the unique opportunity of using the synergy of a dense network of observations, available on routinely basis, but homogenized for HyMeX, or especially deployed during the measurement campaign, to investigate the spatio-temporal variability of atmospheric water vapour in the north-WMed area in relationship with convection development. Previous studies analysed the consistency between the different water vapour data sets during the SOP1 (Chazette et al. 2016b). Few studies focused on the assessment of small-scale integrated water vapour (IWV) variability $(<10 \mathrm{~km} /<1$ day) and/or on the relationship between water vapour and precipitation systems on a larger-scale $(>1000 \mathrm{~km} />$ 1 day; e.g. Van Baelen et al. 2011; Winschall et al. 2012; Chazette et al. 2016a; Lee et al. 2016, 2017).

Using a multispatial scale approach, in this study, we use the synergy of moisture-measuring instruments available during the Intensive Observation Period 12 (IOP 12) to document the evolution and distribution of tropospheric water vapour in relation to the occurrence of HPSs in the north-WMed. Ground-based and airborne observations, as well as space-borne retrievals are combined to obtain a 3-D representation of atmospheric moisture. Highresolution convection permitting numerical weather prediction COSMO model simulations are used to complement the observations and the recent online trajectory module of COSMO helps us calculate online air parcel trajectories in relation with the convection activity in the area. The goal of the present study is to investigate several aspects of the moisture variabilityHPSs relationship during IOP12 in the north-WMed, (a) the variability of tropospheric water vapour and the ability of available observations to properly sample this on different scales, and (b) the role of water vapour as a precursor of heavy precipitation activity in the area. This paper is structured as follows: Section 2 outlines the experimental and modelling setup. Section 3 describes the synoptic situation that dominates over the investigation region between 9 and 14 October, as well as the convection activity and life cycle of the relevant storms in this period. The precipitation distribution, as well as the accompanying lightning 
121 activity, is also discussed. In Section 4, the pre-convective environment leading to HPSs in 122 the investigation areas is assessed by detailed joint evaluation of observations and derived 123 calculations. This part is followed by a detailed analysis of the spatial and temporal 124 distribution of atmospheric humidity in Section 5. The transport, horizontal distribution and 125 vertical stratification on different scales over the north-WMed are discussed. Section 6 closes 126 this study with the summary of findings and conclusions.

\section{Observational and modelling setup}

\subsection{Observations}

Water vapour-related observations covering the north-WMed area between 9 to 14 October, including the IOP12, are used in this investigation, combining spaceborne and in situ observations from ground-based (Figure 1) and airborne platforms. A short description is provided in the following,

(a) Spaceborne information

The RDT product is used in addition to lightning and precipitation information for a detailed analysis of the life cycle of convective storms during the selected investigation period. This product was developed by a team of specialists from the national meteorological institutes from Spain (AEMET), France (Météo-France), Sweden (SMHI) and Austria (ZMAG), as part of the Satellite Application Facility to support Nowcasting and Very Short range Forecasting (SAFNWC), hosted by the European Organisation for the Exploitation of Meteorological Satellites (EUMETSAT). It applies an algorithm to combine the Spinning Enhanced Visible and InfraRed Imager (SEVIRI) onboard Meteosat second generation (MSG) and lightning data from ZEUS lightning detection network 
145 (operated by the National Observatory of Greece) to identify and track convective systems ranging from single isolated cells to mesoscale convective complexes (NWC SAF, 2014). The visualization tool developed by Météo-France uses colours to mark the development stadium of any identified storm. The available data is presented in an animated form in a 15 min temporal resolution.

- Moderate Resolution Imaging Spectroradiometer (MODIS)

In this investigation, MODIS is utilized in order to study the IWV content of the troposphere from the radiance measurements performed by the imaging spectrometers on board the polar-orbiting platforms Terra (crossing the Equator at $1030 \mathrm{LT}$ ) and Aqua (crossing the Equator at 1330 LT). IWV is derived by applying an algorithm to IR spectral radiances retrievals obtained with clear sky conditions during either day or night-time (Gao and Kaufman 2003). The result is a highly spatially resolved gridded data set $(5 \times 5$ $\mathrm{km}$ ) of IWV, mapping the whole Earth's surface every one or two days. The employed data set for this study is a daily average of both Terra and Aqua observations made available on a grid spacing of $1^{\circ} \times 1^{\circ}$.

\section{- NOAA CPC Morphing Technique (CMORPH)}

This product provides precipitation estimates during the investigation period in a gridded data set derived from microwave observation instruments placed in different low orbiter satellites. Microwave measurements from the Special Sensor Microwave Imager (SSM/I) aboard the Defence Meteorological Satellite Program satellites (DMSP-13, -14 and -15), the Advanced Microwave Sounding Unit-B (AMSU-B), on-board the National Oceanic and Atmospheric Administration spacecraft's (NOAA-15, -16, -17 and -18 spacecraft's), the Advanced Microwave Scanning Radiometer-Earth Observing System (AMSR-E) of the Aqua spacecraft and the passive Microwave Imager of the Tropical Rainfall Measuring Mission satellite (TMI-TRMM) are combined by means of the Morphing Technique (Joyce et al. 2004). This procedure makes use of infrared derived motion 
171 vectors to propagate the microwave imagers' features to locations where no microwave 172 data were obtained at a specific time (Stampoulis et al. 2013). This renders the technique 173 flexible regarding its applicability to any microwave satellite source. In addition, it offers 174 a wide coverage $\left(60^{\circ} \mathrm{S}\right.$ to $\left.60^{\circ} \mathrm{N}\right)$, and a high temporal and spatial resolution, 30 minutes 175 and $8 \mathrm{~km}$ at the Equator. The data set is produced by the Climate Prediction Center (CPC) 176 of the National Weather service (NWS) of the USA and covers the period between 1998 177 and 2015.

178 (b) Ground-based information

\section{- Radiosondes}

180 Measurements from about 25 radiosounding stations in the HyMeX investigation area 181 (Figure 1) are used for this research effort. On a regular basis, these measurements provide atmospheric profile information at least twice a day (0000 UTC and 1200 UTC). During SOP1, several of these stations either launched additional sondes at 0600 and 1800 the collected data being less than $1 \mathrm{hPa}$ (about 100 vertical levels) in comparison to regular soundings with generally about 20 vertical levels), all in order to provide a more detailed picture of the vertical distribution of atmospheric variables prior to and during the IOPs. Among these, seven stations were newly established for the purposes of the HyMeX SOP1 campaign.

The network of radiosonde stations is additionally used to calculate convection-related parameters as indicators of the atmospheric degree of stability/instability, namely the Convective Available Potential Energy (CAPE; Moncrieff and Miller 1976), the Convective Inhibition (CIN; Colby 1984) and the KO-index (Andersson et al. 1989). The KO-index is estimated based on the equivalent potential temperature at 500, 700, 850 and $1000 \mathrm{hPa}$ (following the recommendations by Bolton 1980), it describes the potential of 
deep convection to occur as a consequence of large-scale forcing (Andersson et al. 1989; Khodayar et al. 2013). Generally, regions with KO-index $<2 \mathrm{~K}$ and large-scale lifting are identified as favourable for deep convection. Parcel theory (50 hPa ML (Mixed Layer) parcel) and virtual temperature correction (Doswell and Rasmussen 1994) are applied to these calculations.

\section{- Ground-based GPS}

A dense network of Global Positioning System (GPS) stations, which provide IWV information, covering the north-WMed were jointly reprocessed by IGN LAREG (Institut National de l'Information Géographique et Forestière - LAboratoire de Recherche en Géodésie) and e-GEOS S.p.A., ASI/CGS (Agenzia Spaziale Italiana/Centro di Geodesia Spaziale) and made available for the HyMeX scientific community (Bock et al. 2016). One of the highlights of this dataset is its dense and large coverage, provided it was obtained by commonly processing the raw measurements of 25 European, national and regional GPS networks. The post-processing GIPSY/OASIS II v6.2 software was used to process the total delays in the zenith direction (ZTD) and surface level pressure and mean temperature at the stations location were obtained from the AROME model in its westMediterranean configuration (AROME-WMED) and ERA-Interim analysis respectively. The dataset is available up to a 5 minute temporal resolution (the nominal sampling frequency) and also in 1-hourly and 3-hourly averaged data sets. In this study, the 1hourly averaged product is used.

\section{- Boundary Layer pressurized balloons (BLBP)}

Lagrangian trajectories of specific humidity, temperature, pressure and horizontal wind can be obtained by means of Boundary Layer Pressurized Balloons (BLPBs) flying at a nearly constant height (Doerenbecher et al. 2016). For HyMeX SOP1, the Centre National d'Études Spatiales (CNES) measured and processed the BLPB BAMED SOP1 dataset 
221 which is made available in 2.5 minute averages of 30 -second samples, excluding time windows with less than four measurements available. The different launch dates were selected according to the forecasted conditions which were most propitious to reach targeted heavy precipitation areas during the campaign. Specifically, for IOP12 a total of 4 balloons were launched from the Mahon site $\left(4^{\circ} 15^{\prime}-39^{\circ} 51^{\prime}\right.$; Balearic Islands); two on the 11 October 2012, at $~ 0200$ and 0400 UTC and two on the 14 October 2012, at 0600 derived from the BLPB trajectories and that obtained from the ground-based water vapour Raman Lidar (WALI) showed a root mean square error of less than $1.3 \mathrm{~g} \mathrm{~kg}^{-1}$ for the SOP1 period over the Balearic Islands (Chazette et al. 2016b). This highlights the good quality of the humidity measurements.

\section{- Ground-based Raman lidars BASIL (Candillargues) and WALI (Menorca)}

The Raman Lidar BASIL (Di Girolamo et al. 2006, 2009a) is very effective in the characterization of atmospheric temperature and water vapour mixing ratio profiles throughout the troposphere, both in daytime and night-time conditions, providing accurate and high time- and space-resolution measurements of these two thermodynamic parameters, with the main goal of characterizing the water vapour inflow in the Gulf of Lion, which is heavily feeding precipitating systems. The system was deployed in an atmospheric 'supersite' located in Candillargues $\left(43^{\circ} \mathrm{N}, 4^{\circ} \mathrm{E}\right.$, elevation: $\left.1 \mathrm{~m}\right)$ and operated from 5 September to 5 November 2012 (Figure 1). Besides atmospheric temperature and water vapour, BASIL also provides measurements of particle backscatter at 355, 532 and $1064 \mathrm{~nm}$, particle extinction at 355 and $532 \mathrm{~nm}$, and particle depolarization at 355 and 532 nm (Di Girolamo et al. 2009b, 2012). During HyMeX-SOP 1, water vapour mixingratio measurements were calibrated based on the comparison with the simultaneous radiosondes, with the radiosonde launching facility being located approximately $100 \mathrm{~m}$ 
south-east of the lidar station. A mean calibration coefficient for water vapour mixing ratio measurements was estimated based on approximately 50 comparisons.

The Water Vapour Lidar (WALI) described in Chazette et al. (2014) is additionally used to monitor the water vapour mixing in the lower troposphere over the WMed during the period of interest. The lidar was located in La Ciutadella (4000'00" $\mathrm{N}$ and $\left.3^{\circ} 50^{\prime} 20^{\prime \prime} \mathrm{E}\right)$ on Menorca Island (Spain, see Figure 1). The measurement protocol is explained in Chazette et al. (2016b). During HyMeX SOP1, the absolute deviation between the water vapour mixing ratio profiles from WALI and derived from meteorological balloon soundings launched from Palma de Mallorca was assessed to be less than $0.5 \mathrm{~g} \mathrm{~kg}^{-1}$ for a vertical resolution of $30 \mathrm{~m}$. The maximum range of the zenith-pointing lidar was $\sim 6-7$ and $1 \mathrm{~km}$ during night-time and daytime, respectively, depending on the atmospheric transmission, mainly limited by the presence of aerosols or/and clouds.

\section{- Lightning Network}

The EUropean Cooperation for LIghtning Detection (EUCLID 2014) is a collaboration of national lightning detection networks with the aim to identify and detect lightning all over Europe. Within our investigation area, 32 sensors from different networks are positioned. All the lightning data are detected by means of electromagnetic sensors, which send raw data to a central analyser. Each sensor detects the electromagnetic signal emitted by the lightning return stroke. This technology uses GPS satellite signals for time information. For each lightning stroke, the main parameters are recorded, namely, the time of the event, the impact point (latitude and longitude), the current intensity and polarity, and the number of subsequent strokes. This data provides information about the position and even intensity of isolated and organised convective systems.

\section{(c) Airborne Information}


271 The airborne differential absorption lidar (DIAL) LEANDRE 2 was installed on board the ATR-42 aircraft of Service des Avions Français Instrumentés pour la Recherche en Environnement (SAFIRE), which operated from the Montpellier airport during SOP1 (also see Chazette et al. 2016b; Di Girolamo et al. 2016; Lee et al. 2016, among others). Details concerning the design of LEANDRE 2 and the standard DIAL signal processing procedure are given in Bruneau et al. (2001a, 2001b). During IOP12, LEANDRE 2 was operated mostly in zenith-pointing mode, except for a small portion of the flight performed over the Gulf of Lion on 11 October when it performed nadir-pointing observations. LEANDRE 2 carries out water vapour mixing ratio measurements with a precision ranging from less than $0.1 \mathrm{~g} \mathrm{~kg}^{-1}$ at $4.5 \mathrm{~km}$ above sea level to less than $0.4 \mathrm{~g}$ $\mathrm{kg}^{-1}$ near the surface for an along-beam resolution of $150 \mathrm{~m}$ and accumulation of 100 individual profiles, corresponding to an along-track resolution of approximately $1 \mathrm{~km}$ for an ATR-42 flying speed of $100 \mathrm{~m} \mathrm{~s}^{-1}$. Systematic errors associated with the LEANDRE 2 system are typically not exceeding $0.1 \mathrm{~g} \mathrm{~kg}^{-1}$ (Bruneau et al. 2001b).

- $\quad$ oo- 128

Do-128 (Corsmeier et al. 2001) flew mainly around and over Corsica from 11 September to 11 October 2012 as a part of the Karlsruhe Institute of Technology (KIT) participation in HyMeX-SOP 1. It is equipped with instruments (in a nose boom attached on the front) for measuring air temperature, humidity, wind direction and speed, among others.

\subsection{COSMO model and online trajectory module}

291 The non-hydrostatic limited-area weather prediction model Consortium for Small-scale

292 Modelling (COSMO), developed by the German Weather Service (DWD, Shättler et al. 293 2008), is employed in this investigation with horizontal grid spacing of about $7 \mathrm{~km}$ and $2942.8 \mathrm{~km}$, and 40 and 50 vertical levels, respectively. COSMO-2.8 km explicitly resolves deep convection (Weisman et al. 1997) and shallow convection is parameterized with the help of 
296 the reduced Tiedtke scheme (Tiedtke 1989), whereas in COSMO-7 km convection is 297 parameterized with the Tiedtke scheme (Tiedtke 1989). Details about the setup for all 298 physical parameterizations are found in Baldauf et al. (2011). The European Centre for 299 Medium-Range Weather Forecasts (ECMWF) analysis data with a horizontal resolution of 300 about $0.25^{\circ}$ is used as initial and boundary conditions for the COSMO-7 km run, while this is 301 used as forcing for the higher resolution COSMO-2.8 km. The COSMO-7 km and $2.8 \mathrm{~km}$ model domains extend from about $15^{\circ} \mathrm{W}$ to $22^{\circ} \mathrm{E}-25^{\circ} \mathrm{N}$ to $50^{\circ} \mathrm{N}$ and $10^{\circ} \mathrm{W}$ to $20^{\circ} \mathrm{E}-30^{\circ} \mathrm{N}$ to $46^{\circ} \mathrm{N}$, respectively.

304 Online Lagrangian trajectories based on grid-scale wind velocities are used to study 305 mesoscale flows in the COSMO model (Miltenberger et al. 2013). The Lagrangian depiction 306 of atmospheric processes largely contributed in the last years to advance our understanding. 307 Lagrangian studies allowed the identification of atmospheric rivers (e.g. Ramos et al. 2015; 308 2016) and warm conveyor belts (WCB; e.g. Wernli and Davis 1997), the evaporative and 309 moisture water sources for precipitation (e.g. Sodemann et al. 2008; Liberato et al. 2012) or 310 the origin of air parcels feeding convective cells (e.g. Wang and Xue 2012). We use in this 311 study the online Lagrangian trajectories module of COSMO to assess the most likely origin 312 and path of air parcels contributing to the occurrence of HPS during the IOP12 on the WMed.

313 A great advantage of the online trajectory contrary to any other offline option is the calculation of the trajectory with wind field inputs at every model time step $(\sim 25 \mathrm{~s}$ for the high-resolution simulations, this value shortens with increasing model resolution), whereas 316 offline trajectories are calculated with temporal resolutions from $1 \mathrm{~h}$ to $6 \mathrm{~h}$. Because of the 317 forward computation of the online trajectories, the specification of the starting points is not a 318 trivial task. A priori knowledge of the interesting starting regions and times is required. 319 Following Duffourg and Ducrocq (2013) we started the simulation about 4 days before 320 intense convection activity in the north-western Mediterranean to consider the moisture of the 
321 low-level feeding flow provided by evaporation over the Mediterranean and the transport

322 from remote sources such as the Atlantic Ocean and/or Africa. The whole simulation period 323 covers the 8 October 2012 to the 16 October 2012. To avoid missing relevant information we 324 start trajectories every $0.5^{\circ}$ over the entire investigation domain every $12 \mathrm{~h}$ starting 4 days 325 before the event. In total more than 50000 trajectories are calculated. To identify from all 326 estimated trajectories the contributing air parcels to each HPS and their origins the following 327 criteria are applied, (a) all air parcels are started $10 \mathrm{~m}$ over the surface to capture moisture 328 uptake regions. We assume that at this height the trajectories start in the boundary layer and 329 trajectories intersection with the terrain is avoided (Miltenberger et al. 2013), (b) air parcel 330 trajectories have to reach at least $\sim 7000 \mathrm{~m}$ (Wernli 1997), and (c) air parcels have to release 331 at least $5 \mathrm{~g} \mathrm{~kg}^{-1}$ of the specific humidity in a 6-hour interval within the target area (Winschall 332 et al. 2014; Sodemann et al. 2008; James et al. 2004).

\section{Meteorological situation}

\subsection{Large-scale situation}

The synoptic situation over the Mediterranean area during the analysed period was generally dominated by a long-wave trough that approached from the west and remained over the Iberian Peninsula for several days, producing favourable conditions for the development of deep moist convection (Figure 2).

340 On 9 October, the WMed was under the influence of a slowly weakening ridge receding 341 before the appearance of a trough approaching from the eastern Atlantic, which developed 342 from a cut off low that moved across the ocean in the previous days (Figure 2a). It merged 343 with a quickly approaching and elongating trough over the north-western Atlantic in the course of 10 October. On the following day, the trough over the Atlantic moved further south- 
345 eastwards (at $0000 \mathrm{UTC}$ its axis stretched along the western Iberian coast). Until late 11

346 October, a weak low-pressure area moved eastwards along the southern French coast reaching

347 the Gulf of Genoa (Figure 2b). To the west of it, in the upper levels, a well pronounced short-

348 wave trough simultaneously crossed that area, advecting warm and humid air from over the

349 sea. Ahead of it moved an area of strong local lifting (between 20 and $40 \mathrm{hPa}$ in 6 hours). A

350 slight Potential Vorticity (PV) anomaly that accompanied this short-wave trough (not shown)

351 additionally strengthened the already existing instability. During the day, the long-wave

352 trough moved further eastwards so that around 1800 UTC its major axis lay across central

353 France and the eastern coasts of Spain. It was swiftly followed by another secondary trough

354 approaching from the west. On 12 October, this secondary trough was located already on the

355 eastern side of the long-wave trough, crossing over Corsica, central Italy and the Balkan. At

3560000 UTC, the weak surface low with accompanying fronts was located over the Gulf of

357 Genoa, in the area of strong convective activity of IOP12. It moved ahead of this secondary

358 trough, slightly weakening on its way, and reached the Balkan around midnight. Its presence

359 was related to strong convective activity as well as an HPS over central and southern Italy, as

360 well as over the Adriatic Sea. Westerly and north-westerly mid-tropospheric winds brought in

361 humid air. The upper level pattern from the previous day remained almost unchanged on 13

362 October (Figure 2c). The axis of the main long-wave trough moved further east and, by

363 approximately 1800 UTC, stretched along the western Italian coast.

364 3.2. Convective activity

365 Between 9 and 13 October 2012, covering the IOP12 period (11 and 12 October), the 366 convective activity in the WMed was very intense. During these days convective activity was 367 observed to move eastwards (Figure 3, Table 1).

368 Intense convective activity on 10 October was initiated in the early afternoon in the form of 369 several storms over central Spain. One of these, with the longest life span, started at $\sim 1345$ 
370 UTC some $100 \mathrm{~km}$ to the west of Madrid and moved in the north-eastward direction. At

3712000 UTC, it begun to weaken but approximately two hours later it merged with a newly

372 developed storm, whereupon it turned south-east towards the north-eastern Spanish coast

373 from where it continued eastwards until it dissipated over the sea at $\sim 0945$ UTC on the

374 following day (marked "A"; Figure 3a). It lasted for about $19.5 \mathrm{~h}$ and its anvil grew in this

375 time to almost $39000 \mathrm{~km}^{2}$. This storm produced relatively moderate amounts of precipitation,

376 i.e. $50 \mathrm{~mm}$ of $24-\mathrm{h}$ accumulated precipitation measured by rain gauges and CMORPH

377 estimates, which occurred only over land. Lightning activity in this area was strong

378 throughout the whole convective period, which lasted till the end of the day (Figure 4a).

379 The main IOP12 MCS developed in the evening of 11 October over the north-WMed as two

380 initially independent storms. By looking at the 15-min radar reflectivity scan images for this

381 particular analysis (not shown), it could be observed that one of these storms (marked "B1" in

382 Figure $3 b$ ) initiated at $~ 1930$ UTC also as two separate convective cells, one over the eastern

383 French Riviera and the other some $30 \mathrm{~km}$ to the south of it over the sea. The second storm

384 (marked "B2") resulted from the merging of three smaller cells, which occurred at $\sim 2100$

385 over the sea some $100 \mathrm{~km}$ to the west of Corsica. Before it happened, numerous single-cell

386 storms developed in the zone between the Balearic Islands and Corsica from approximately

3871800 UTC embedded within and moving eastwards with a broad cloud band stretching from

388 southern France to northern Africa. Before those two main storms merged to form a MCS

389 (marked "C"), the northern one lasted for about 7 hours growing up to $37000 \mathrm{~km}^{2}$ and the 390 southern one for around 4.5 hours reaching over $23000 \mathrm{~km}^{2}$ cloud top surface. At around 391 midnight, both storms merged creating a cluster with the anvil's area of over $130000 \mathrm{~km}^{2}$.

392 CMORPH captured the initiation of the main IOP12 MCS as two separate storms (not 393 shown), which produced high and spatially concentrated amounts of precipitation (up to 75 $394 \mathrm{~mm}$ in 6 hours); precipitation visibly diminished as the storms merged and propagated 395 eastwards developing in to the main IOP12 MCS existing till the early morning hours of 12 
396 October (Figure 4b). Storm "D" (Figure 3c) started as two cells between Corsica and Italy at

397

398

399

400

401

402

403

404

405

406

407

408

409

410

411

412

413

414

415

416

417

418

419

420

around 0200 UTC on 12 October and within the following hour it merged with a storm over central Italy, which developed shortly before midnight on 11 October. In its 8-h-long life it crossed central Italy in south-eastern direction and grew up to $93000 \mathrm{~km}^{2}$. This MCS was responsible for the HPS over central Italy on that day. On 12 October, an area of strong precipitation could be observed over the vast region stretching between Corsica, Sicily and the Balkan Peninsula, which was directly connected with the activity of the IOP12 MCSs (Figure 4c). Rain gauges in central Italy measured over $150 \mathrm{~mm}$ in about six hours, but about $75 \mathrm{~mm}$ over the eastern Spanish coast, Majorca and Sicily. According to CMORPH data, the convective storms over the south-WMed also caused HPSs, during which over $150 \mathrm{~mm}$ precipitation could be measured in a period lasting between 6 and 12 hours. The lightning pattern shows that dense lightning activity was present everywhere between southern France and northern Sardinia where the main MCS developed. On 13 October convection occurred over the south-western and central Mediterranean (including northern Africa, southern Italy and the Balkan area); however only over Sicily did a MCS develop and remained active and intense in the second half of the day (marked "M" in Figure 3d) producing about $50 \mathrm{~mm}$ accumulated precipitation over land in about 6 hours (Figure 4d), but more than $150 \mathrm{~mm}$ rain over the sea within the same time period (not shown). The lightning data show that the majority of storms over the south-western and southern Mediterranean were merely continuations of convective activity that initiated on the previous day. Most of them were moving in the eastern direction and dissipated in the early afternoon.

\section{Daily cycle of convection-related atmospheric conditions}

An assessment of the temporal evolution and potential dependencies of convection-related atmospheric conditions on sub-daily scale for those areas where HPS occurrence was 
421 registered is shown in Figure 5. The following areas are considered, Area1 covers the north422 eastern Iberian Peninsula, Area2 covers Corsica, Area3 is located in central Italy, and Area4 423 includes Sicily in southern Italy (Figure 1). We are particularly interested in assessing the 424 similarities and differences between the Areal preconditions leading to heavy precipitation. 425 For each region hourly lightning sums using cloud-to-ground lightning data measured by the 426 EUCLID network, as well as the hourly rain rates from CMORPH measurements are 427 considered. We selected one representative radiosounding station for each area (Barcelona for 428 Area1, Figure 5a; KIT-INRA for Area2, Figure 5b; Pratica Di Mare for Area3, Figure 5c; 429 Trapani Birgi for Area4, Figure 5d; positions of the radiosoundings are in Figure 1) to study 430 atmospheric stability and humidity stratification. The radiosounding profile information were 431 used to compute CAPE, KO-index, CIN, as representative of atmospheric instability and 432 inhibition conditions and the mean relative humidity $(\mathrm{RH})$ averaged in the layer between 850 433 and $700 \mathrm{hPa}$, as a measurement of the humidity content in the mid-troposphere. Additionally, 434 we included the IWV data from the nearest GPS stations (all located at similar heights; Figure 435 1), which provided information on the humidity contained in the entire troposphere above the 436 station with 1 hourly temporal resolution.

437 The general picture confirms a shift of convective activity and moisture maxima from west to 438 east. Lightning activity was well correlated with maxima of precipitation as an indicator of 439 deep convection in agreement with previous observations (Soriano et al. 2001). In all cases 440 the convective activity occurred in periods of maximum IWV ( 30 to $\left.45 \mathrm{~kg} \mathrm{~m}^{-2}\right)$. An upper 441 threshold of about $45 \mathrm{~kg} \mathrm{~m}^{-2}$ was identified. Total column atmospheric humidity experiences a 442 notable increase prior to HPSs, mostly in relationship with a change, up to $5 \mathrm{~g} \mathrm{~kg}^{-1}$, in the 443 lower and mid-levels of the atmosphere (below $700 \mathrm{hPa}$ ). The upper atmospheric levels 444 (above $\sim 500 \mathrm{hPa}$; not shown) do not reveal any significant variation. Changes in the lower445 troposphere in the pre-convective environment were associated to winds predominantly from 
446 the south-southwest and from the west in the layers above. Those stations with higher 447 moisture content in the lower troposphere reveal a lower Lifting Condensation Level (LCL) 448 and a smaller difference between the LCL and the Level of Free Convection (LFC), which is 449 conducive to a more rapid formation of thunderstorms (not shown). For example, an increase 450 of about $4 \mathrm{~g} \mathrm{~kg}^{-1}$ in the lower PBL moisture, registered at southern France (NIM 451 radiosounding station) prior to CI resulted in a decrease of LCL-LFC from $\sim 175 \mathrm{hPa}$ on 10 452 October 1200 UTC to $\sim 50 \mathrm{hPa}$ on 11 October 1200 UTC. Furthermore, directly related with 453 the increase of moisture in the lower tropospheric levels an increase in atmospheric instability 454 and a decrease in atmospheric inhibition are also identified prior to HPSs.

455 In the mid-troposphere the relative humidity was very high, $>75 \%$, in all deep convection 456 events leading to HPSs. Observations of the convective evolution in Area1, after the main 457 event, show a dry mid-troposphere inhibiting deepening of convective systems despite a 458 further low-tropospheric moisture increase. This supports previous investigations which 459 showed that high amounts of moisture in the mid-troposphere, which could be also due to 460 convection itself, favour deepening of convection and precipitation intensity and its absence 461 constrains its evolution (e.g. Khodayar et al. 2010; Lee et al. 2016). Similar developments are 462 identified in the pre-convective environments of all stations affected by HPSs, which 463 evidences the crucial role of water vapour horizontal distribution and stratification on the 464 initiation and intensification of convection.

465 In all cases except Area4, the period of severe convection activity was followed by a humidity 466 decrease (back to values observed at least 24-h prior to CI) resulting from boundary layer 467 winds turning their direction to westerly. The advection of dry air, thus, the moisture decrease 468 was concomitant with an equivalent potential temperature decrease and an increase in 469 atmospheric stability (CAPE $\sim 0 \mathrm{~J} \mathrm{~kg}^{-1}$; KO-index $\sim 1 \mathrm{~K}$ ), not favouring further intensification 470 of convection and suppressing any possibility of CI. In Area4, westerly and south-westerly 471 winds continued advecting moist air over southern Italy after the main convection activity 
472 developed in the area, which resulted in a further initiation of deep moist convection in this 473 region on 13 October, primarily affecting the Balkans.

474 Despite the important commonalities listed above relevant differences are identified regarding 475 the build-up time period of the moisture changes and the resulting vertical stratification. 476 Figure 6 helps us illustrate these findings showing the interdependence between atmospheric 477 instability and atmospheric moisture changes with respect to convective evolution at two of 478 the affected areas/radiosounding stations, Area1/Barcelona (deep convection was observed at 479 about 11 October at 0000 UTC; max prec $\sim 50 \mathrm{~mm}^{-1}$ day $^{-1}$ ) and Area4/Trapani Birgi (a MCS 480 developed in the morning and maintained until mid-day on 13 October; max prec $\sim 200 \mathrm{~mm}$ 481 day $^{-1}$ ). Despite a strong Areal increase of IWV $\sim 20 \mathrm{~kg} \mathrm{~m}^{-2}$ prior to CI, maximum local 482 precipitation in Areal did not exceed $50 \mathrm{~mm} \mathrm{day}^{-1}$ (this is the area registering the lowest 483 precipitation rates). This increase occurred in a period of $36 \mathrm{~h}$ and maximum IWV values 484 were up to $45 \mathrm{~kg} \mathrm{~m}^{-2}$. All atmospheric levels up to $500 \mathrm{hPa}$ were affected, particularly the 485 mid- and low-atmosphere. In this $36 \mathrm{~h}$ period, an increase of about $3 \mathrm{~g} \mathrm{~kg}^{-1}$ was observed in 486 the $900 \pm 50 \mathrm{hPa}$ layer in the last $24 \mathrm{~h}$, the same increase occurred in the $700 \pm 50 \mathrm{hPa}$ layer but 487 only in the first $12 \mathrm{~h}$. With the increasing moisture the atmosphere became more unstable, as 488 testified by the raising CAPE values to about $1200 \mathrm{~J} \mathrm{~kg}^{-1}$ (decreasing $\mathrm{KO}$-index to $-10 \mathrm{~K}$ ). 489 Contrary to the observed increase in Area1 the episode of moisture build-up over Area4 was 490 rather sudden (about $10 \mathrm{~kg} \mathrm{~m}^{-2}$ in $\sim 12 \mathrm{~h}$ ), short-lived (duration of maximum about $12 \mathrm{~h}$ ) and 491 the maximum IWV did not reach more than $\sim 35 \mathrm{~kg} \mathrm{~m}^{-2}, \sim 10 \mathrm{~kg} \mathrm{~m}^{-2}$ lower than in Area1. In 492 this area the most intense precipitation event was registered, maximum precipitation of about $493200 \mathrm{~mm}$ in 6 hours was measured around 1200 UTC on 13 October. In contrast to the other 494 regions considered, a rapid and significant moisture increase of about $5 \mathrm{~g} \mathrm{~kg}^{-1}$ in $6 \mathrm{~h}$ 495 characterizes the low-troposphere (in Area1 the same maximum in the lower-PBL was 496 reached after a $24 \mathrm{~h}$ period), while a weaker change occurs in the mid-troposphere. This 
497 resulted in very high CAPE values of about $2000 \mathrm{~J} \mathrm{~kg}^{-1}$, KO-index $\sim-14 \mathrm{~K}$, in a period where 498 no CIN constrains deep convection in the area.

499 A similar situation is observed in Area2 and Area3, in which the IWV increase was sudden 500 and rather quick, $\sim 12 \mathrm{~h}$, and the atmosphere did not remain this moist for more than $\sim 12 \mathrm{~h}$ 501 and did not exceed $35 \mathrm{~kg} \mathrm{~m}^{-2}$. In Area2, between the surface and $700 \mathrm{hPa}$ a specific humidity 502 increase over $3 \mathrm{~g} \mathrm{~kg}^{-1}$ is registered. Moderate CAPE $\sim 500 \mathrm{~J} \mathrm{~kg}^{-1}$, and KO-index $\sim-9 \mathrm{~K}$ 503 suggest that deep convection is possible in the area only under strong large-scale forcing. In 504 Area3, the specific humidity increased by some $3.5 \mathrm{~g} \mathrm{~kg}^{-1}$ on average between 750 and 600 $505 \mathrm{hPa}$, whereas an increase of about $2 \mathrm{~g} \mathrm{~kg}^{-1}$ is identified below $900 \mathrm{hPa}$ resulting in a sudden 506 increase of CAPE to $\sim 800 \mathrm{~J} \mathrm{~kg}^{-1}$. The combination of these changes with the lack of 507 atmospheric inhibition, $\mathrm{CIN} \sim 0 \mathrm{~J} \mathrm{~kg}^{-1}$, favoured deep convection and intense precipitation in 508 the area. More than $150 \mathrm{~mm}$ in $6 \mathrm{~h}$ were measured in the area.

509

\section{Moisture transport and distribution over the north Western Mediterranean}

511 To complement the information provided by the single observations regarding the evolution 512 of moisture with respect to convective activity in the selected subdomains, a combination of 513 MODIS and GPS-derived IWV (Figure 7) and observations from the two ground-based water 514 vapour Raman Lidars, WALI at Menorca (Balearic Islands) and BASIL at Candillargues 515 (Southern France; Figure 10) and from the BLPBs (Figure 11a) and the airborne water vapour 516 lidar (Figure 11b,c,d) are investigated. These measurements should complement each other 517 and their joint evaluation is expected to provide an improved representation of atmospheric 518 moisture variability and its implication for convective activity on different spatiotemporal 519 scales. 
521 The combination of MODIS and GPS-derived IWV allows the reconstruction of the spatial 522 distribution of tropospheric water vapour over a large area, being a well-known limitation of 523 observational networks such as the GPS (Khodayar et al. 2016b). To jointly evaluate both 524 data sets, comparisons have been performed at the location of each GPS-station. Maximum 525 differences of about $2 \mathrm{~kg} \mathrm{~m}^{-2}$ have been found, which could be related with cloud 526 contamination in the MODIS IR data (dry bias) and with the time sampling differences. No 527 bias correction has been applied in this case. This information is combined with simulated 528 high-resolution, $7 \mathrm{~km}$ and $2.8 \mathrm{~km}, \mathrm{COSMO}$ winds at different levels $(500,700,850,950 \mathrm{hPa}$ 529 and $10 \mathrm{~m}$ ), in order to assess the most likely transport path of the atmospheric moisture during 530 IOP12. Furthermore, the computation of the COSMO online Lagrangian trajectories helped us 531 to further assess the trajectories that air parcels mostly contributing to the HPS followed 532 serving as a qualitative indicator of the most likely transport pathway (Figure 8a) and origin 533 (Figure 8b) of moisture.

534 On the 9 October 2012, MODIS-derived IWV shows two hot-spots with IWV values reaching 535 about $50 \mathrm{~kg} \mathrm{~m}^{-2}$, over the Atlantic - between Portugal and north-Africa - and east of Tunisia 536 (Figure 7a). Following the south-westerly transport of humid air from the Atlantic towards the 537 centre and north of the Iberian Peninsula a gradual humidity surge of about $10 \mathrm{~kg} \mathrm{~m}^{-2}$ could 538 be observed throughout the day, from about 25 to $35 \mathrm{~kg} \mathrm{~m}^{-2}$. On 10 October, moisture 539 advection continues over the Iberian Peninsula and the moisture amount over the already 540 relatively humid Mediterranean $\left(30-35 \mathrm{~kg} \mathrm{~m}^{-2}\right)$ rose up to $45 \mathrm{~kg} \mathrm{~m}^{-2}$ forming a humid zone 541 along the eastern Spanish coast bending eastward across the Balearic Sea up to Sardinia 542 (Figure 7b). Instability began to increase over the Iberian Peninsula, reaching CAPE values of 543 ca $1000 \mathrm{~J} \mathrm{~kg}^{-1}$ and KO-index of about $-15 \mathrm{~K}$ over Barcelona (Figure 9a). The first storms 544 initiated over this area (Figure 3a) in the presence of some moderate CIN over Barcelona (ca $\left.54580 \mathrm{~J} \mathrm{~kg}^{-1}\right)$ and a relatively strong one $\left(250 \mathrm{~J} \mathrm{~kg}^{-1}\right)$ over Zaragoza, about $250 \mathrm{~km}$ apart. Several 546 orographically induced convergence lines formed over central and eastern Spain on that day, 
547 some as early as $12 \mathrm{~h}$ prior to the formation of the first storms in the region. The position of 548 these convergence lines did not change much during the day, but winds became stronger as 549 the day progressed (a change from 1 to about $8 \mathrm{~m} \mathrm{~s}^{-1}$ was measured). This low-level wind 550 convergence in addition to the presence of large scale lifting of about $20 \mathrm{hPa} \mathrm{h}^{-1}$ acted as 551 triggering mechanisms in the area. KO-index in the order of -15 to $-20 \mathrm{~K}$ and high $\mathrm{CAPE}(\sim$ $552900 \mathrm{~J} \mathrm{~kg}^{-1}$ ) in combination with no CIN occur also over Corsica, in agreement with high 553 moisture values observed e.g. at the INRA radiosounding station (Figure 5b). However, no 554 convection developed in this area due to the absence of a triggering mechanism, contrary to 555 the previous situation on the north-eastern Spain.

556 The eastward transport of moist air continued on 11 October (Figure 7c). This eastward 557 gradual moisture increase was strongly correlated (spatially and temporarily) with the moist 558 air advection associated with the surface low accompanied by the shortwave trough aloft 559 (Figure 2). Accompanying the strong increase of moisture along the southern French coast 560 and Majorca, then over Corsica (reaching about $40 \mathrm{~kg} \mathrm{~m}^{-2}$ from a value of $\sim 20 \mathrm{~kg} \mathrm{~m}^{-2} 24 \mathrm{~h}$ 561 before), CAPE levels increased (between 1000 and $1750 \mathrm{~J} \mathrm{~kg}^{-1}$; Figure 9b) particularly 562 between the Gulf of Lion and northern Algeria. CIN levels in that same region were the 563 highest in the south (up to $150 \mathrm{~J} \mathrm{~kg}^{-1}$ over Dar El Beïda) and the lowest in the north (between 5640 and $10 \mathrm{~J} \mathrm{~kg}^{-1}$ over southern France) where deep convection initiated, which led to the 565 development of the main IOP12 MCS (Figures 3 and 4). Also in this case, a convergence zone 566 could be identified from the near-surface wind and buoy observations (not shown) prior to CI, 567 also captured by COSMO $2.8 \mathrm{~km}$. The convergence line southeast of the Gulf of Lion was 568 already present at about 1200 UTC because of the merging of north-easterly and south569 westerly winds, which additionally advected moist air from over the sea. The $500 \mathrm{hPa}$ level 570 was a region of strong air ascent (between $20 \mathrm{hPa} \mathrm{h}^{-1}$ over southern France and almost $40 \mathrm{hPa}$ $571 \mathrm{~h}^{-1}$ over the sea) associated with the short-wave through. In agreement with these 572 observations and complementing this information, the computation of the COSMO online 
573 Lagrangian trajectories showed four main regions from where air parcels contributed to the 574 formation of the HPSs: a) the eastern Atlantic Ocean, b) the land over the Iberian Peninsula, 575 c) the north-western Mediterranean, and d) the north-eastern Africa region. Regions a, b and c 576 mainly contributed to the formation of the HPSs over central and eastern Spain on 10 577 October, whereas regions $\mathrm{c}$ and d play this role for the main IOP12 HPS on 11 and 12 578 October. Different time scales ranging from days to hours are needed for the air parcels 579 originating at these regions to reach the target areas. Remote regions such as the Atlantic 580 Ocean and Africa require about 3-4 days whereas closer regions such as the Mediterranean 581 itself need few hours to a day to reach their destination.

582 The ground-based water vapour Raman Lidars WALI and BASIL (Figure 10), the BLPBs 583 (Figure 11a) and the airborne lidar LEANDRE 2 (Figure 11b1, 11b2, 11b3) additionally 584 provided some valuable insight into the atmospheric moisture conditions directly over the 585 region where the IOP12 MCS initiated. The south to north moisture gradient and the 586 increasing moistening of the atmosphere preceding deep convection, which determined CI 587 location in the area, was well captured with high resolution. At Menorca, WALI (Figure 10a) 588 reveals a very moist low PBL, with specific humidity values up to about $15 \mathrm{~g} \mathrm{~kg}^{-1}$ and 589 reaching up to ca $1.5 \mathrm{~km}$, from 9 October until early morning on 12 October. At $0000 \mathrm{UTC}$ on 59012 October, deep moist updrafts are seen, probably in relationship with strong updrafts 591 transporting moist air from the lower levels. This is in contrast with the dry atmosphere in 592 southern France as evidenced by the BASIL lidar observations for the period 10 to 12 October 593 (Figure 10b). Maximum values of water vapour up to $10 \mathrm{~g} \mathrm{~kg}^{-1}$ are seen reaching about $1 \mathrm{~km}$, 594 in the period between 11 October at 1200 UTC and 12 October at 0000 UTC. The BLPBs 595 captured a high level of variability in the area between the Balearic Islands and Corsica on 11 596 October. In the initial part of their eastward trajectories, both balloons measured moisture 597 amounts of roughly $10 \mathrm{~g} \mathrm{~kg}^{-1}$. This changed as they both turned northwards where, in both 598 cases, specific humidity levels increased to about $15 \mathrm{~g} \mathrm{~kg}^{-1}\left(\sim 6-10 \mathrm{~g} \mathrm{~kg}^{-1}\right.$ moister than 
599 observations on the same region on the 14 October). On this day, a short Do-128 flight 600 conducted from 0700 till 1100 UTC over the sea along the north-eastern Corsican coast 601 clearly evidenced that the lower PBL ( $200 \mathrm{~m}$ amsl) in this region was significantly drier, $<5$ $602 \mathrm{~g} \mathrm{~kg}^{-1}$, than the western coast.

603 In agreement with this, the LEANDRE lidar on board of the ATR-42 (between ca 0600 and 6041000 UTC on 11 October over the eastern Gulf of Lion, upstream of convective systems 605 developing over this region at about 1930 UTC) showed a very moist PBL, reaching up to ca $6061.5 \mathrm{~km}$, with specific humidity levels between about 9 and $15 \mathrm{~g} \mathrm{~kg}^{-1}$ (Figure 11b1). On the 607 contrary, on 12 and 14 October (as part of IOP13) in the same area, a shallow PBL reaching 608 up to $0.5 \mathrm{~km}$ was observed with specific humidity values between 6 and $11 \mathrm{~g} \mathrm{~kg}^{-1}$ in this layer 609 (Figures $11 \mathrm{~b} 2$ and 11b3). Figure 7d shows that after this period moisture content decreases 610 over the Iberian Peninsula, France and Corsica and Sardinia Islands (by 10 to $20 \mathrm{~kg} \mathrm{~m}^{-2}$ on 611 average) in agreement with the south-eastward progress of notably drier air. In all those 612 regions, it put an end to severe convection.

613 A change to southerly winds in the lower-troposphere over eastern-Africa and over the sea 614 east of Tunisia, starting at about 1800 UTC on the 11 October, is responsible for the transport 615 of the moist air mass over the sea towards central Italy (an IWV increase of about $15 \mathrm{~kg} \mathrm{~m}^{-2}$ 616 in less than 24 hours is registered). These changes were closely correlated with the drop in 617 instability (CAPE and KO-index) in the western part of the investigation area, and a gradual 618 increase everywhere in the east, beginning over Corsica and moving southeast towards 619 southern Italy (Figure 9c). Under these conditions convection activity over central Italy 620 started entering in its dissipation stage at around 1600 UTC on 12 October. Preceded by a 621 IWV increase in the area of Sicily, from around $30 \mathrm{~kg} \mathrm{~m}^{-2}$ measured at 1800 UTC on 12 622 October to around $40 \mathrm{~kg} \mathrm{~m}^{-2}$ at 0700 UTC on 13 October, and accompanying CAPE values in 623 the range $1500-2000 \mathrm{~J} \mathrm{~kg}^{-1}$, KO-index close to $-20 \mathrm{~K}$ and almost no CIN, the severe MCS 
624 (Figures 3 and 4) producing another HPS, with precipitation sums up to $200 \mathrm{~mm}$ in 6 hours, 625 occurred in southern Sicily. Several convergence lines were also present over western Italy 626 and the northern Tyrrhenian Sea prior to the onset convection in the night between 11 and 12 627 October. In this case, these formed only some $3 \mathrm{~h}$ prior to convective CI. Their effect was 628 strengthened by a shortwave through aloft and the orography of the area which played an 629 important role in this case. The front approaching from the northwest forced the moist air 630 ahead of it (IWV $\sim 40 \mathrm{~kg} \mathrm{~m}^{-2}$ ) to rise over the western slopes of the mountain ranges 631 stretching along the Apennine Peninsula. On 13 October (Figure 7e), dry air masses 632 continued to flow in from the north-western direction over Spain, France, and north- and 633 central Italy. By the end of the day the IWV levels dropped to values as low as $10-15 \mathrm{~kg} \mathrm{~m}^{-2}$. 634 The most humid air was concentrated over the south-eastern part of our investigation area 635 (Algeria and Tunisia to the south), and over the Tyrrhenian Sea and to the south and west of 636 Sicily, where till noon moisture levels rose up to $40 \mathrm{~kg} \mathrm{~m}^{-2}$. In this area, a low-level wind 637 convergence zone could be identified resulting from the merging of southerly winds 638 transporting moisture from the sea east of Tunisia, and northerly winds transporting moisture 639 from the Mediterranean area between Sardinia and central Italy. This convergence zone 640 favoured the concentration of the convective activity around Sicily, especially west of it over 641 the sea. Everywhere the humidity started to decrease in the early evening and remained low in 642 the following days. Figure 9d shows that instability decreased in almost the whole region and 643 CIN increased by 50 to $70 \mathrm{~J} \mathrm{~kg}^{-1}$ with respect to the values measured 24 hours earlier. 644 Convection was still active over the Tyrrhenian Sea and Apennine Peninsula in the afternoon 645 and evening of 13 October, but it was no longer as intensive as on the previous day.

646 647

\section{Conclusions}


648 The investigation of the spatio-temporal evolution of atmospheric moisture variability 649 contributing to the HPS over the WMed region is an open question whose progress is 650 generally hampered by the lack of water vapour observations, thus mostly restricted to 651 modelling studies. This study profits from the rare opportunity to gather a diverse set of 652 observational data sets providing a representation of atmospheric moisture across spatial and 653 temporal scales in the framework of HyMeX. This helped us demonstrating that the sampling 654 of water vapour spatial inhomogeneities on different scales is crucial for the understanding of 655 the timing and location of deep convection. With this purpose, we use three types of 656 observations, passive remote sensing water vapour observations such as MODIS, ground657 based in-situ measurements such as radiosounding profile information, BLPB, ground-based 658 water vapour Raman lidars and GPS-derived IWV, as well as airborne water vapour DIAL 659 measurements. We combine this information with high-resolution COSMO model simulations 660 to provide insight into the origin and pathways of air parcels contributing to the occurrence of 661 the MCSs and their triggering mechanisms. Regarding this last point, the identification of 662 low-level wind convergence lines prior to each deep convection episode in the area turned out 663 to be crucial for the initiation and location of convection in the area, which is in agreement 664 with previous investigations in different mid-latitude regions (e.g. Khodayar et al. 2013).

665 Four areas of intense deep convection activity affect the investigation area during IOP12. 666 Convective activity starts in north-east Spain (Area1) moving eastward toward Corsica 667 (Area2), where intensification is observed and finally affecting central (Area3) and southern 668 Italy (Area4). Italy was the most affected area, with intense precipitation being registered, $669150-200 \mathrm{~mm} / 6 \mathrm{~h}$, while precipitation rates in the range 50 to $100 \mathrm{~mm}$ in $24 \mathrm{~h}$ were recorded in 670 the other affected areas.

671 The main findings of this study are summarized below, 
672 - The high spatial and temporal coverage of GPS-IWV observations allowed to 673 adequately sampling the west-to-east moisture transport within the north-WMed. All 674 convective episodes leading to HPS occurred in environments with IWV values 675 between 30 and $45 \mathrm{~kg} \mathrm{~m}^{-2}$, being these upper threshold values common in the region 676 for the autumn period of 2012 (e.g. Khodayar et al 2016a).

677 - Large moisture changes, up to $20 \mathrm{~kg} \mathrm{~m}^{-2}$, were identified prior to each convective 678 episode leading to HPS. More intense events were not related to the situations in 679 which higher IWV is reached, but rather the build-up time and vertical distribution of 680 these increases were found to be crucial for the evolution and intensification of the 681 HPS, thus on the severity of the event.

682 - The most intense events reveal a rapid, 6-12 h, IWV increase in the order of $10 \mathrm{~kg} \mathrm{~m}^{-2}$ 683 (Area2, Area3 and Area4), whereas less intense events show a larger increase, $\sim 20 \mathrm{~kg}$ $684 \mathrm{~m}^{-2}$ but in a longer time period $24 \mathrm{~h}$ to $36 \mathrm{~h}$ (Area1).

685 - Total column moisture changes were mainly related to differences in the lower and 686 mid-troposphere. Almost no change in the atmospheric moisture distribution was 687 observed at $\sim 500 \mathrm{hPa}$ or above. The mid-atmosphere, $\sim 850$ to $700 \mathrm{hPa}$, remained 688 very moist during the pre- and convective periods, with RH values in excess of $75 \%$, 689 favouring deep convection development. In the lower-troposphere, changes up to $5 \mathrm{~g}$ $690 \quad \mathrm{~kg}^{-1}$ are observed.

691 - The atmospheric stability conditions were as expected largely affected by these 692 changes. The larger/faster the increase of the water vapour content in the low- and 693 mid-troposphere, the stronger the impact on the atmospheric stability conditions and 694 the strength of convection. Large-sudden increases in CAPE are identified preceding 695 explosive convection yielding high precipitation amounts in a few hours. 
- A decrease of the LCL and a reduction of LCL-LFC are identified in those situations following an increase of moisture in the lower-troposphere. This suggests that moist air parcels become more easily buoyant, thus favouring initiation of deep convection and the rapid formation of deep thunderstorms.

- Moister and deeper boundary layers with updraughts reaching up to $2 \mathrm{~km}$ are identified in those pre-convective environments leading to HPS, whereas dry, shallow boundary layers are found everywhere else with updraughts not higher than about 1 $\mathrm{km}$.

- Spatial moisture inhomogeneities in the lower PBL, up to $4 \mathrm{~g} \mathrm{~kg}^{-1}$ in less of $100 \mathrm{~km}$, have been shown to determine the location of CI over the sea.

- Particularly for this IOP12, the more intense HPS is seen to receive air parcels, hence moisture contributions simultaneously from different sources resulting in a largesudden increase of moisture in the lower atmosphere leading to explosive HPSs, as previously discussed. Whereas in the less intense events advection from a particular direction is seen to control moisture changes in the lower and mainly mid-troposphere probably in relation to synoptic conditions dominating the dynamics of the atmosphere. After the occurrence of heavy precipitation, a strong decrease of atmospheric moisture content is seen with the same or larger magnitude of the previous increase.

We can conclude that the combined analysis of the available observational data sets provides on different scales adequate information about atmospheric moisture variability relevant to HPS occurrence. The synergetic analysis of the measurements helped us understanding the mechanisms and pre-convective conditions leading to deep convection in the area. Limitations on the use of single instrumentations are pointed out in this study. The development of a lidar network to measure water vapour could be of great help in the understanding and forecast of 
721 extreme events. The sampling of the interplay between the moisture evolution on different

722 scales, from the large- to the smaller scale, as well as the lapse rate in which this occurs is 723 crucial to improve our understanding of HPSs. Additionally, this study demonstrates that the 724 misrepresentation of this variability in time and space should be carefully evaluated in model 725 simulations as a crucial factor responsible for wrong CI and precipitation simulations. This 726 study focuses on a complex single IOP; therefore, it would be of interest to extend the 727 investigation to a large number of events, including other types of convective situations. 728 Although the relevance of the vertical distribution of moisture and related changes for the 729 occurrence of HPSs was already pointed out in the region in Khodayar et al. (2016c), the 730 relationship with the severity of the event and the build-up time has not been previously 731 discussed. Therefore, further analysis regarding these characteristics will be necessary to 732 assess the generality of our results. 


\section{Acknowledgements}

746

747

748

749

750

751

752

753

754

755

756

757

758

759

760

761

762

763

764

765

766

This work is a contribution to the HyMeX program supported by CNRS MISTRALS, ANR IODA-MED Grant ANR-11-BS56-0005, ANR MUSIC Grant ANR-14-CEO1-014 and ANR REMEMBER Grant ANR-12-SENV-001. The authors thank the HyMeX database teams (ESPRI/IPSL and SEDOO/Observatoire Midi-Pyrénées) for their help in accessing the data, as well as all SOP1 field teams who performed measurements during this time. We further acknowledge U. Corsmeier, A. Wieser and the whole crew of the Do-128 and ATR-42 for performing and facilitating aircraft measurements. Airborne data was obtained using the ATR-42 Environment Research Aircraft operated and managed by Service des Avions Français Instrumentés pour la Recherche en Environnement (SAFIRE), which is a joint entity of CNRS, Météo-France \& CNES. The SAFIRE staff is thanked for their support during the SOP1. The authors are grateful to D. Bruneau, P. Genau, C. Merlet, T. Deleporte, S. Bastin, C. Kocha, C. Lavaysse and R. Meynadier (LATMOS) as well as F. Blouzon and A. Abchiche (DT/INSU) for operating the LEANDRE 2 system aboard the ATR-42 during the HyMeXSOP1. Finally, we thank EUCLID (EUropean Cooperation for LIghtning Detection) for providing the lightning data and A. Doerenbecher and all teams responsible for the BLPB measurements. The first author's research is supported by the Bundesministerium für Bildung und Forschung (BMBF). 


\section{References}

769 Andersson, T., Andersson, M., Jacobsson, C., Nilsson, S. (1989). Thermodynamic indices for 770 forecasting thunderstorms in southern Sweden. Meteorol Mag 118(1404), 141-146.

771 Baldauf, M., Seifert, A., Förstner, J., Majewski, D., Raschendorfer, M., and Reinhardt, T., 772 (2011). Operational Convective-Scale Numerical Weather Prediction with the COSMO 773 Model: Description and Sensitivities. Mon. Wea. Rev., 139(12), 3887-3905. 774 doi.org/10.1175/MWR-D-10-05013.1.

775 Bevis, M., Businger, S., Herring, T. A., Rocken, C., Anthes, R. A., and Ware, R. H. (1992). 776 GPS meteorology: Remote sensing of atmospheric water vapor using the global positioning 777 system, J. Geophys. Res., 97(D14), 15787-15801. doi:10.1029/92JD01517.

778 Bock, O., Bosser, P., Pacione, R., Nuret, M., Fourrié, N. and Parracho, A. (2016). A high779 quality reprocessed ground-based GPS dataset for atmospheric process studies, radiosonde 780 and model evaluation, and reanalysis of HyMeX Special Observing Period, QJRMS, 142(S1), 781 56-71. doi: 10.1002/qj.2701.

782 Bolton, D. (1980). The Computation of Equivalent Potential Temperature. Mon Weather Rev, 783 108(7), 1046-1053. doi: 10.1175/1520-0493(1980)108<1046:TCOEPT>2.0.CO;2.

784 Bony, S., R. Colman, V.M. Kattsov, R.P. Allan, C.S. Bretherton, J. Dufresne, A. Hall, S. 785 Hallegatte, M.M. Holland, W. Ingram, D.A. Randall, B.J. Soden, G. Tselioudis, and M.J. 786 Webb (2006). How Well Do We Understand and Evaluate Climate Change Feedback 787 Processes?. J. Climate, 19, 3445-3482, https://doi.org/10.1175/JCLI3819.1 
789 Bruneau, D., Quaglia, P., Flamant, C., Meissonnier, M., Pelon, J. (2001a). Airborne lidar 790 LEANDRE II for water-vapor profiling in the troposphere. I: System description. Appl. Opt., $79140(21), 3450-3461$.

792

793 Bruneau, D., Quaglia, P., Flamant, C., Pelon, J. (2001b). Airborne lidar LEANDRE II for 794 water-vapor profiling in the troposphere. II: First results. Appl. Opt., 40(21), 3462-3475. 795

796 Chazette, P., Marnas, F., and Totems, J. (2014). The mobile Water vapor Aerosol Raman 797 LIdar and its implication in the framework of the HyMeX and ChArMEx programs: 798 application to a dust transport process. Atmos. Meas. Tech., 7(6), 1629-1647. 799 doi:10.5194/amt-7-1629-2014.

800

801 Chazette P., Flamant, C., Raut, J.-C., Totems J., and Shang, X., (2016a). Tropical moisture 802 enriched storm tracks over the Mediterranean and their link with intense rainfall in the Cevennes803 Vivarais area during HyMeX. QJRMS, 142(S1), 320-334.

804 Chazette P., Flamant, C., Shang, X.,Totems, J., Raut, J.-C., Doerenbecher, A., Ducrocq, V., 805 Fourrié, N., Bock, O., Dorenbecher, A., and Cloché, S. (2016b). Multi-instrument and multi-model 806 assessment of atmospheric moisture variability over the Western Mediterranean during HyMeX. 807 QJRMS, 142(S1), 7-22.

808

809 Colby, F.P., (1984). Convective inhibition as a predictor of convection during AVE-SESAME 810 II. Mon. Wea. Rev. 112(11), 2239-2252. 
812 Corsmeier, U.; Hankers, R.; Wieser, A. (2001). Airborne turbulence measurements in the 813 lower troposphere onboard the research aircraft Dornier 128-6, D-IBUF. Meteorol. Zeit., 10, 814 4, 315-329. DOI: 10.1127/0941-2948/2001/0010-0315

815

816 Crook, N. A., (1996). Sensitivity of moist convection forced by boundary layer processes to 817 low-level thermodynamic fields. Mon. Wea. Rev., 124(8), 1768-1785.

818

819 Di Girolamo, P., Behrendt, A., and Wulfmeyer, V. (2006). Spaceborne profiling of 820 atmospheric temperature and particle extinction with pure rotational Raman Lidar and of 821 relative humidity in combination with differential absorption Lidar: performance simulations. 822 Appl. Opt., 45(11), 2474-2494. doi: 10.1364/AO.45.002474.

823

824 Di Girolamo, P., Summa, D., Ferretti, R. (2009a). Multiparameter Raman Lidar 825 Measurements for the Characterization of a Dry Stratospheric Intrusion Event. J. Atm. Ocean. 826 Tech., 26(9), 1742-1762, doi: 10.1175/2009JTECHA1253.1.

827

828 Di Girolamo, P., Summa, D., Lin, R. F., Maestri, T., Rizzi, R., Masiello, G. (2009b). UV 829 Raman lidar measurements of relative humidity for the characterization of cirrus cloud 830 microphysical properties. Atmos. Chem. Phys., 9(22), 8799-8811. doi:10.5194/acp-9-87998312009.

832

833 Di Girolamo, P., Summa, D., Bhawar, R., Di Iorio, T., Cacciani, M., Veselovskii, I., Dubovik, 834 O., Kolgotin, A. (2012). Raman lidar observations of a Saharan dust outbreak event: 835 Characterization of the dust optical properties and determination of particle size and 836 microphysical parameters. Atmos. Envir., 50, 66-78. doi: 10.1016/j.atmosenv.2011.12.0612. 
838 Di Girolamo, P., Flamant, C., Cacciani, M., Richard, E., Ducrocq, V., Summa, D., Stelitano, 839 D., Fourrié, N., and Saïd, F. (2016). Observation of low-level wind reversals in the Gulf of 840 Lion area and their impact on the water vapour variability. QJRMS, 142(S1), 153-172. doi: $841 \quad 10.1002 / q j .2767$.

842 Doerenbecher, A., Basdevant, C., Drobinski, P., Bernard, F., Durand, P., Cocquerez, P., 843 Verdier, N., and Vargas, A. (2016). Low atmosphere drifting balloons: Platforms for 844 environment monitoring and forecast improvement, Bull. Amer. Meteorol. Soc., 97(9), 1583845 1599. doi:10.1175/BAMS-D-14-00182.1.

846

847 Doswell, C.A. III, and Rasmussen, E.N. (1994). The effect of neglecting the virtual 848 temperature correction on CAPE calculations. Wea. Forecasting, 9(4), 619-623.

849 Doswell C. A. III, Brooks, H. E., and Maddox, R. A. (1996). Flash Flood Forecasting: An 850 Ingredients-Based Methodology. Wea. Forecasting, 11(4), 560-581. doi: 851 http://dx.doi.org/10.1175/1520-0434(1996)011<0560:FFFAIB>2.0.CO;2.

852 Drobinski P., Ducrocq, V., Alpert, P., Anagnostou, E., Béranger, K., Borga, M., Braud, I., 853 Chanzy, A., Davolio, S., Delrieu, G., Estournel, C., Filali Boubrahmi, N., Font, J., Grubišić, 854 V., Gualdi, S., Homar, V., Ivančan-Picek, B., Kottmeier, C., Kotroni, V., Lagouvardos, K., 855 Lionello, P., Llasat, M. C., Ludwig, W., Lutoff, C., Mariotti, A., Richard, E., Romero, R., 856 Rotunno, R., Roussot, O., Ruin, I., Somot, S., Taupier-Letage, I., Tintore, J., Uijlenhoet, R. 857 and Wernli, H., (2014). HyMeX: A 10-year multidisciplinary program on the Mediterranean 858 water cycle. Bull. Amer. Meteor. Soc., 95(7), 1063-1082. doi: 859 http://dx.doi.org/10.1175/BAMS-D-12-00242.1. 
860 Ducrocq, V., Braud, I., Davolio, S., Ferretti, R., Flamant, C., Jansa, A., Kalthoff, N., Richard, 861 E., Taupier-Letage, I., Ayral, P., Belamari, S., Berne, A., Borga, M., Boudevillain, B., Bock, 862 O., Boichard, J., Bouin, M., Bousquet, O., Bouvier, C., Chiggiato, J., Cimini, D., Corsmeier, 863 U., Coppola, L., Cocquerez, C., Defer, E., Delanoë, J., Di Girolamo, P., Doerenbecher, A., 864 Drobinski, P., Dufournet, Y., Fourrié, N., Gourley, J. J., Labatut, L., Lambert, D., Le Coz, J., 865 Marzano, F. S., Molinié, G., Montani, A., Nord, G., Nuret, M., Ramage, K., Rison, W., 866 Roussot, O., Said, F., Schwarzenboeck, A., Testor, P., Van Baelen, J., Vincendon, B., Aran, 867 M., and Tamayo, J. (2014). HyMeX-SOP1: The field campaign dedicated to heavy 868 precipitation and flash flooding in the Northwestern Mediterranean. Bull. Amer. Meteor. Soc., 869 95(7), 1083-1100. doi: http://dx.doi.org/10.1175/BAMS-D-12-00244.1.

870 Duffourg, F., and Ducrocq, V. (2013). Assessment of the water supply to Mediterranean 871 heavy precipitation: a method based on finely designed water budgets. Atmos. Sci. Let., 872 14(3), 133-138. DOI: 10.1002/asl2.429.

873 EUCLID (2014). European Coorperation for Lightning Detection. URL www.euclid.org, last 874 accessed on: 9.10.2014

875 Gao, B., and Kaufman, Y. (2003). Water vapor retrievals using Moderate Resolution 876 ImagingSpectroradiometer (MODIS) near-infrared channels. Journal of Geophysical 877 Research, 108(D13).

878 James, P., A. Stohl, N. Spichtinger, S. Eckhardt, and C. Forster (2004), Climatological aspects 879 of the extreme European rainfall of August 2002 and a trajectory method for estimating the 880 associated evaporative source regions, Nat. Hazards Earth Syst. Sci., 4, 733-746. 
882 Joyce, R., Janowiak, J. E., Arkin, P. A. and Xie, P. (2004). CMORPH: A Method that

883 Produces Global Precipitation Estimates from Passive Microwave and Infrared Data at High

884 Spatial and Temporal Resolution. Journal of Hydrometeorology, 5(3), 487-503.

885 Khodayar, S., Kalthoff, N., Wickert, J., Corsmeier, U., Morcrette, C. J., Kottmeier, C. (2010).

886 The increase of spatial data resolution for the detection of the initiation of convection. A case 887 study from CSIP. Meteorol. Z., 19(2), 179-198.

888

889 Khodayar, S., Kalthoff, N., Wickert, J., Kottmeier, C., Dorninger, M.,(2013). High resolution 890 representation of the mechanisms responsible for the initiation of isolated thunderstorms 891 over flat and complex terrains: Analysis of CSIP and COPS cases. Meteorol. Atmos. Phys., 892 119(3-4), 109-124.

893

894 Khodayar, S., Kalthoff, N., Kottmeier, C. (2016a). Atmospheric Conditions Associated with 895 Heavy Precipitation Events in Comparison to Seasonal Means in the Western Mediterranean 896 Region. Climate Dyn. 1-17. doi: 10.1007/s00382-016-3058-y

897 Khodayar, S., Raff, F., Kalthoff, N. and Bock, O. (2016b), Diagnostic study of a high898 precipitation event in the Western Mediterranean: adequacy of current operational networks. 899 Q.J.R. Meteorol. Soc., 142: 72-85. doi:10.1002/qj.2600

900 Khodayar, S., Fosser, G., Berthou, S., Davolio, S., Drobinski, P., Ducrocq, V., Ferretti, R. 901 , Nuret, M. , Pichelli, E., Richard, E. and Bock, O. (2016c), A seamless weather-climate 902 multi-model intercomparison on the representation of a high impact weather event in the 903 western Mediterranean: HyMeX IOP12. Q.J.R. Meteorol. Soc., 142: 433-452. 904 doi: $\underline{10.1002 / q j .2700}$ 
905 Lascaux, F., Richard, E., Keil, C. and Bock, O. (2004). Impact of the MAP reanalysis on the 906 numerical simulation of the MAP IOP2a convective system, ICAM 2003. Meteorol. Z., 13(1), $907 \quad 49-54$.

908

909 Lee, K.-O., Flamant, C., Ducrocq, V., Duffourg, F., Fourrié, N. and Davolio, S. (2016). 910 Convective initiation and maintenance processes of two back-building mesoscale convective 911 systems leading to heavy precipitation events in Southern Italy during HyMeX IOP 13. 912 QJRMS, 142(700), 2623-2635.

913

914 Lee, K.-O., C. Flamant, V. Ducrocq, F. Duffourg, N. Fourrié, J. Delanoë and J. Bech, (2017) 915 Initiation and development of a mesoscale convective system in the Ebro River Valley and 916 related heavy precipitation over north-eastern Spain during HyMeX IOP 15a, Q. J. Roy. 917 Meteorol. Soc., 143, 942-956, doi: 10.1002/qj.2978

918

919 Liberato, M. L. R., Ramos, A. M., Trigo, R. M., Trigo, I. F., Durán-Quesada, A. M., Nieto, 920 R., Gimeno, L., (2012) Moisture Sources and Large-Scale Dynamics Associated With a Flash 921 Flood Event, Lagrangian Modeling of the Atmosphere. Geophysical Monograph Series 200, 922 111-126 DOI: 10.1029/2012GM001244

923

924 Miltenberger, A. K., Pfahl, S., and Wernli, H. (2013). An online trajectory module (version 925 1.0) for the nonhydrostatic numerical weather prediction model COSMO. Geosci. Model 926 Dev., 6(6), 1989-2004. https://doi.org/10.5194/gmd-6-1989-2013. 
928 Moncrieff, M.W, Miller, M.J, (1976). The dynamics and simulation of tropical cumulonimbus 929 and squall lines. QJRMS, 102(432), 373-394.

930

931 Nuissier, O., Ducrocq, V., Ricard, D., Lebeaupin, C., and Anquetin, S. (2008). A numerical 932 study of three catastrophic precipitating events over southern France, I: Numerical framework 933 and synoptic ingredients. QJRMS, 134(630), 111-130.

934

935 Nuissier, O., Joly, B., Joly, A., Ducrocq, V., (2011). A statistical downscaling to identify the 936 Large Scale Circulation patterns associated with Heavy Precipitation Events over southern 937 France. QJRMS, 137(660), 1812-1827.

938

93

SAF

(2014).

SAFNWC

General

information.

URL

940 http://www.nwcsaf.org/HD/MainNS.jsp, last accessed on: 9.10.2014.

941

942 Ramos, A.M., Trigo, R.M., Liberato, M.L.R., Tome, R., (2015) Daily Precipitation Extreme

943 Events in the Iberian Peninsula and Its Association with Atmospheric Rivers, Journal of 944 Hydrometeorology, 16, 579-597 DOI: 10.1175/JHM-D-14-0103.1

945

946 Ramos, A. M., Nieto, R., Tomé, R., Gimeno, L., Trigo, R.M., Liberato, M.L.R., Lavers, D.A., 947 (2016) Atmospheric rivers moisture sources from a Lagrangian perspective, Earth Syst. 948 Dynam., 7, 371-384 DOI: 10.5194/esd-7-371-2016

949

950 Riosalido, R. (1990). Characterization of mesoscale convective systems by satellite pictures

951 during PREVIMET-89. Segundo Simposio Nacional de Predicción Madrid, Instituto Nacional 
952 de Meteorología, 135-148.

953

954 Röhner, L., Nerding, K.-U., and Corsmeier, U., (2016). Diagnostic study of a HyMeX heavy 955 precipitation events over Spain by investigation of moisture trajectories. QJRMS, 142(S1), 956 287-297. DOI: 10.1002/qj.2825.

957

958 Schättler, U., Doms, G., and Schraff, C. (2008), A Description of the Nonhydrostatic 959 Regional COSMO-Model, Part VII: User's Guide, 135 pp., Dtsch. Wetterdienst, Offenbach, 960 Germany.

961 Sherwood, S. C., Roca, R., Weckwerth, T. M., and Andronova, N. G. (2010). Tropospheric 962 water vapor convection and climate. Rev. Geophys., 48(2). doi:10.1029/2009RG000301.

963 Sodemann, H., Schwierz, C., and Wernli, H. (2008). Interannual variability of Greenland 964 winter precipitation sources: Lagrangian moisture diagnostic and North Atlantic Oscillation 965 influence. J. Geophys. Res., 113(D3), D03107. doi:10.1029/2007JD008503.

966 Soriano, L.R., F. de Pablo, and E.G. Díez, (2001). Relationship between Convective 967 Precipitation and Cloud-to-Ground Lightning in the Iberian Peninsula. Mon. Wea. Rev., 129, 968 2998-3003, https://doi.org/10.1175/1520-0493(2001)129<2998:RBCPAC>2.0.CO;2

970 Stampoulis, D., Anagnostou, E. N., and Nikolopoulos, E. (2013). Assessment of High 971 Resolution Satellite-based Rainfall Estimates over the Mediterranean during Heavy 972 Precipitation events. Journal of Hydrometeorologym, 14(5), 1500-1514. 
974 Tiedtke, M., (1989). A Comprehensive Mass Flux Scheme for Cumulus Parameterization in 975 Large-Scale Models. Mon. Wea. Rev., 117(8), 1779-1800. doi.org/10.1175/1520976 0493(1989)117<1779:ACMFSF>2.0.CO;2.

977

978 Van Baelen, J., Reverdy, M., Tridon, F., Labbouz, L., Dick, G., Bender, M., and Hagen, M. 979 (2011). On the relationship between water vapour field evolution and the life cycle of 980 precipitation systems. QJRMS, 137(S1), 204-223. doi:10.1002/qj.785.

981 Wang, Q.-W and Xue, M. (2012). Convective initiation on the 19 July 2002 during IHOP: 982 High-resolution simulations and analysis of the mesoscale structures and convective 983 initiation. J. Geophys. Res., 117, D12107.

985 Weckwerth, T. M., Wilson, J. W., and Wakimoto, R. M., (1996). Thermodynamic variability 986 within the convective boundary layer due to horizontal convective rolls. Mon. Wea. Rev., 987 124(5), 769-784.

988

989 Weckwerth, T. M., Wulfmeyer, V., Wakimoto, R. M., Hardesty, R. M., Wilson, J. W., and 990 Banta, R. M. (1999). NCAR-NOAA Lower-Tropospheric Water Vapor Workshop. Bull. 991 Amer. Meteor. Soc., 80(11), 2339-2357.

992

993 Weckwerth, T.M. (2000). The effect of small-scale moisture variability on thunderstorm 994 initiation. Mon. Wea. Rev., 128(12), 4017-4030. 
995 Weisman, M. L., Skamarock, W. C., and Klemp, J. B., (1997). The resolution dependence of 996 explicitly modeled convective systems. Mon. Wea. Rev., 125(4), 527-548.

997

998 Wernli, B. H. and Davies, H. C. (1997). A Lagrangian-based analysis of extratropical 999 cyclones. I: The method and some applications. QJRMS, 123(538), 467-489. 1000 doi:10.1002/qj.49712353811.

1001

1002 Winschall, A., Pfahl, S., Sodemann, H., and Wernli, H. (2012). Impact of North Atlantic 1003 evaporation hot spots on southern Alpine heavy precipitation events. QJRMS, 138(666), 1004 1245-1258. doi:10.1002/qj.987.

1005

1006 Winschall, A., Sodemann, H., Pfahl, S., and Wernli, H. (2014). How important is intensified 1007 evaporation for Mediterranean precipitation extremes? J. Geophys. Res. Atmos., 119(9), 1008 5240-5256. doi:10.1002/2013JD021175.

1009

1010

1011

1012

1013

1014

1015

1016 
1018 Figures

1019

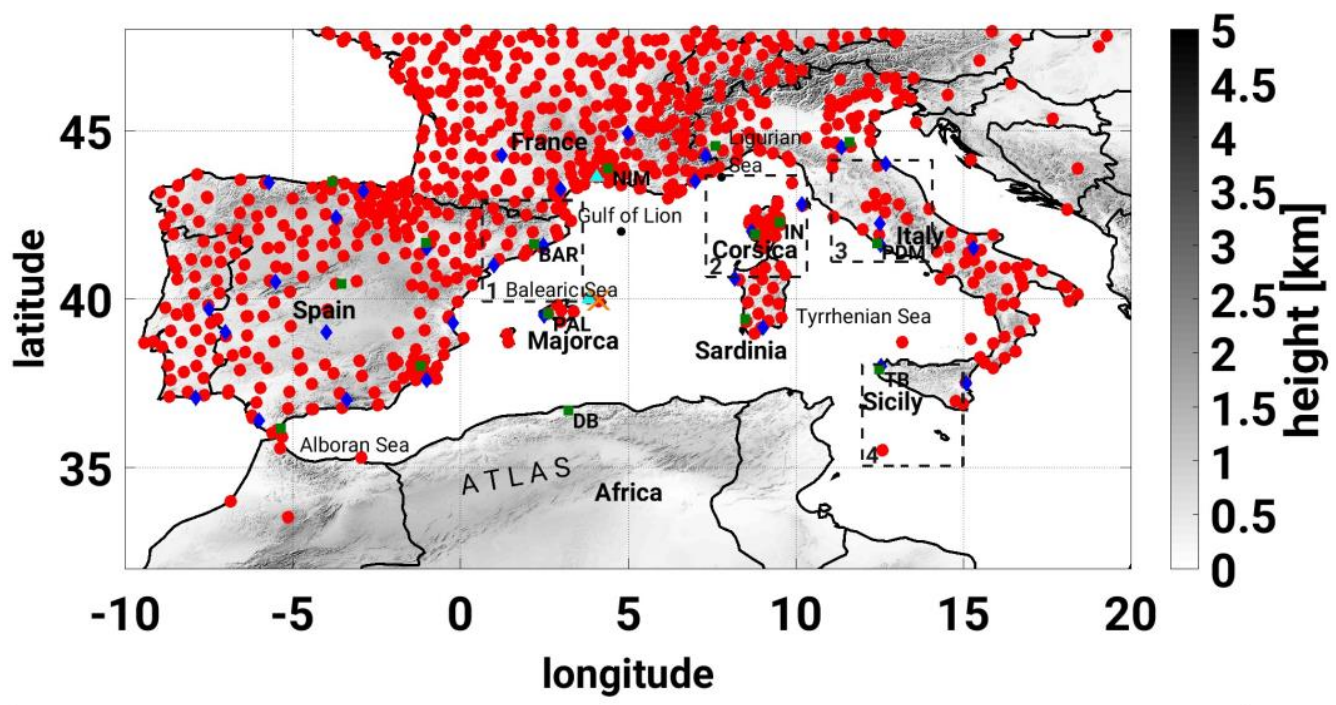

- buoys - GPS stations - lightning stations - radiosoundings $\triangle$ LIDAR stations

Figure 1: Orography of the western Mediterranean region (black-white scale). Subdomains under investigation are delineated with dashed lines and numbered from 1 to 4 . Observations are indicated as follows: GPS network (red), radiosoundings (green), lightning stations (blue), buoys (black), WALI lidar and BASIL lidar (light blue); the orange cross over the southeastern Menorca indicates the Boundary Layer Pressured Balloons (BLPB) launch site at the beginning of the balloon trajectories. Selected radiosounding stations are named as follows 1028 (from left to right) BAR (Barcelona), PAL (Palma), NIM (Nimes), IN (Inra), PDM (Pratica Di 1029 Mare) and TB (Trapani Birgi). 
1031

1032 (a) 09.10.2012 1200 UTC

1033

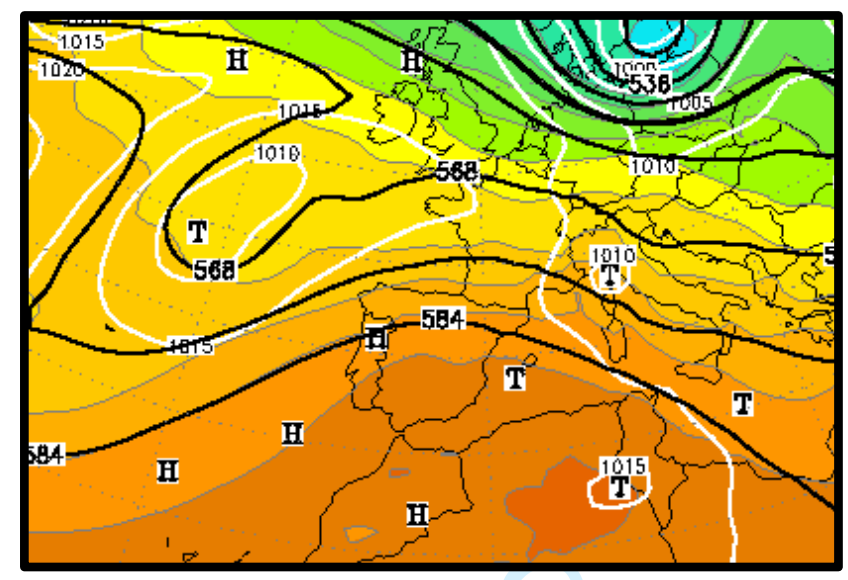

1034 (b) 11.10 .20121200 UTC

1035

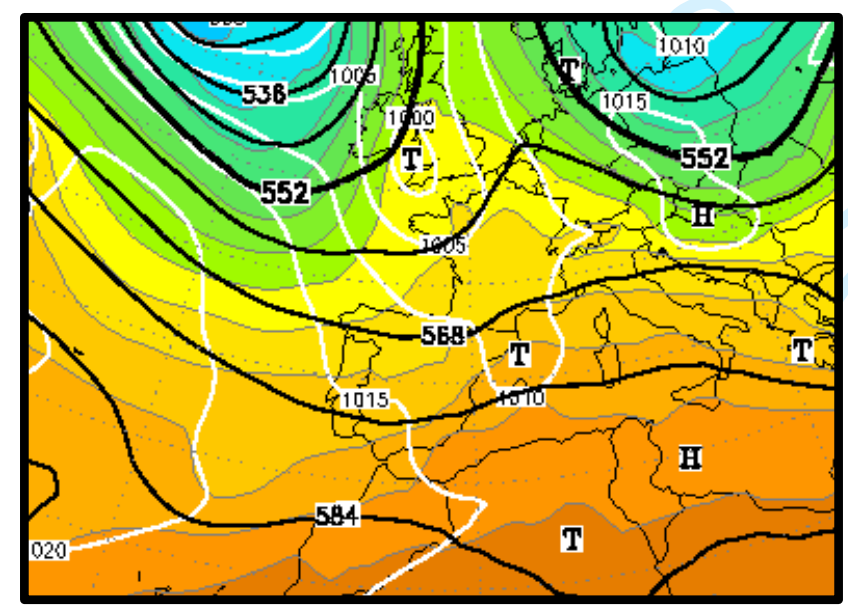

$1036 \quad$ (c) 13.10 .20121200 UTC

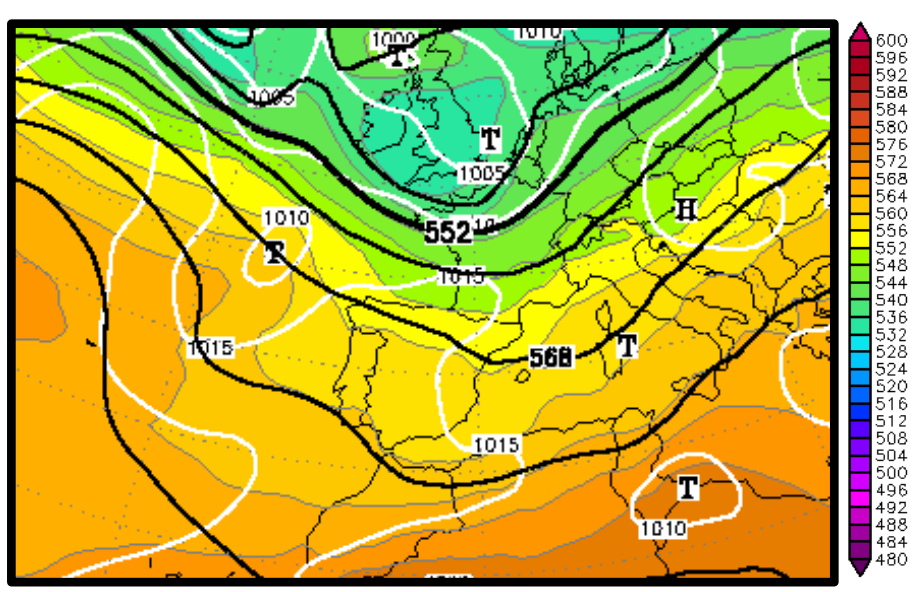


1038

1039 Figure 2: GFS-analysis of $500 \mathrm{hPa}$ geopotential height (gpdgm; black isolines), mean sea1040 level pressure (hPa; white isolines) and relative topography H500-H1000 (gpdgm; colour 1041 scale) at 1200 UTC on the 9, 11 and 13 October 2012 (source: wetter3.de).

1042

1043

1044

1045

1046

1047

1048

1049

1050

1051

1052

1053

1054

1055

1056

59

60 

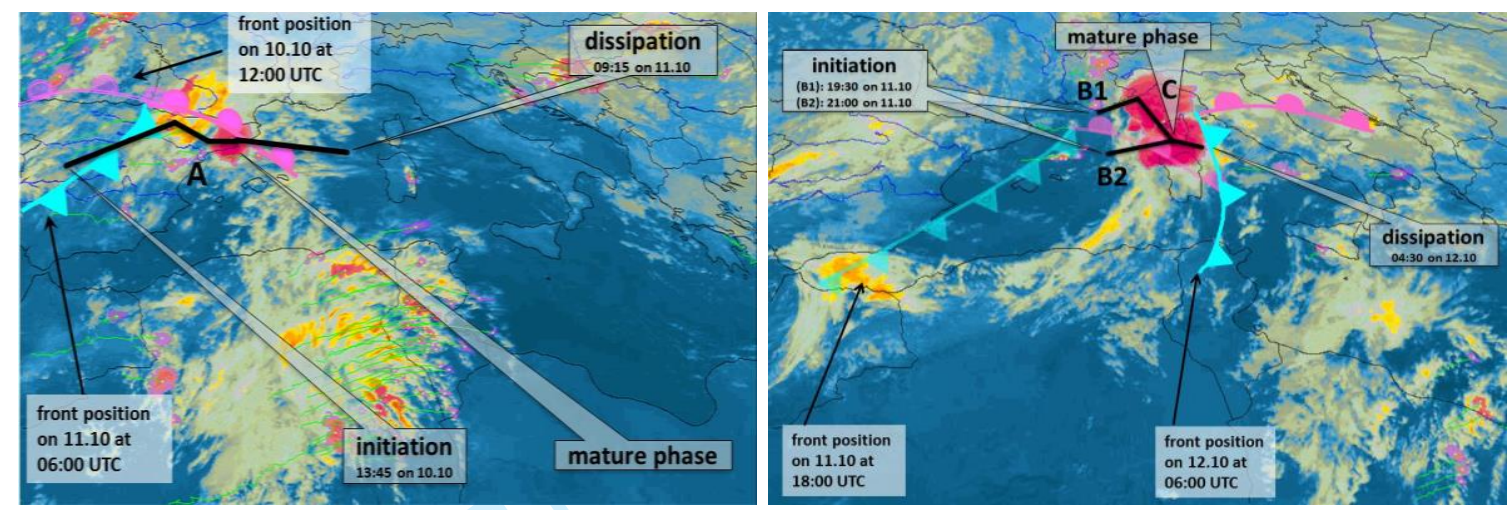

1061

(c) 12.10.2012 at 0500 UTC

(d) 13.10.2012 at 1400 UTC

1062
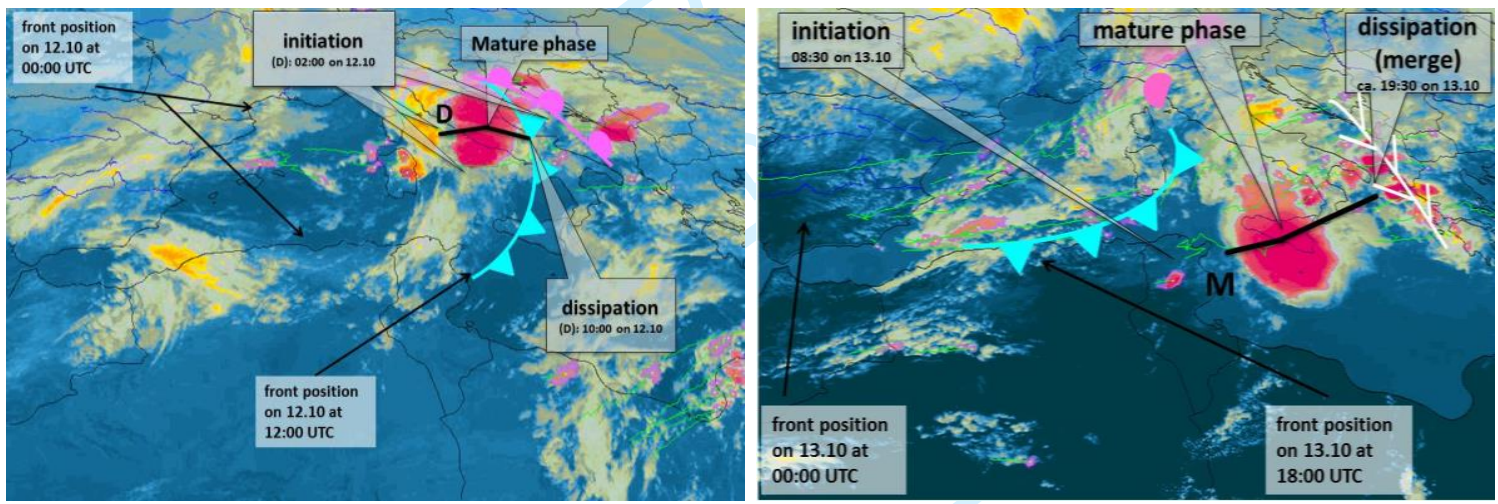

1063

1064 Figure 3: RDT (Rapid Developing Thunderstorm) products based on MSG SEVIRI 1065 brightness temperature images at $10.8 \mu \mathrm{m}$ showing the spatio-temporal development of 1066 convective activity over the Mediterranean region for (a) 11 October 2012 at 0000 UTC, (b) 106712 October 2012 at 0000 UTC, (c) 12 October 2012 at 0500 UTC and (d) 13 October 2012 at 10681400 UTC. All development stages of storms are highlighted using different colours 1069 (yellow=triggering, orange=growing, magenta=mature stadium, violet $=$ split cases). The blue, 1070 pink and white lines represent the position of fronts and convergence lines, respectively. The 
1071 thick black lines locate the path of each storm and the captions indicate the stage of every 1072 convective cell.

$1073 \quad$ (a) 10.10 .2012
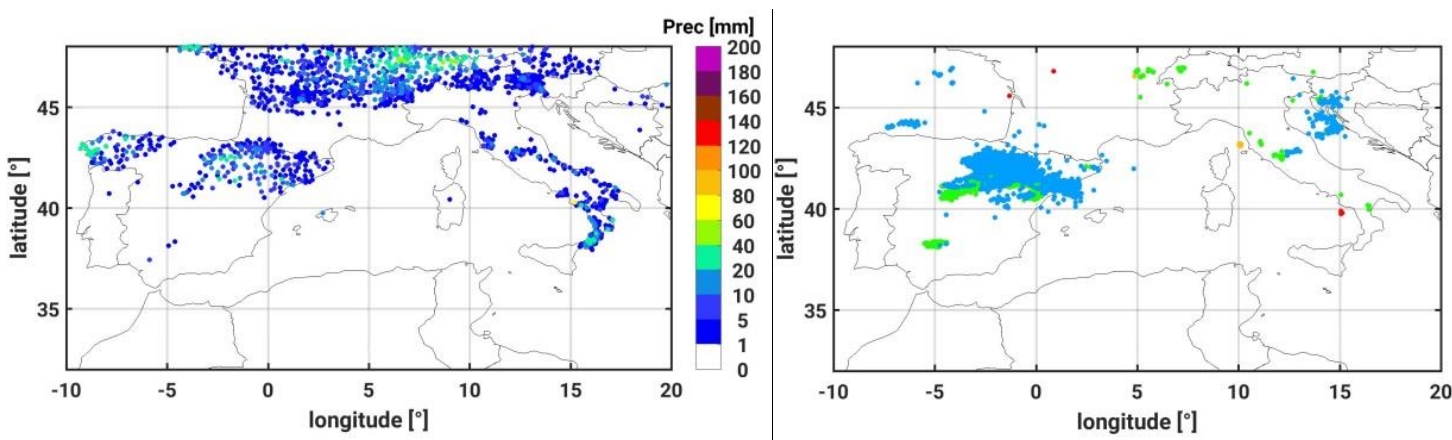

1074

- 0-6 UTC - 6-12 UTC - 12-18 UTC - 18-0 UTC

1075

$1076 \quad$ (b) 11.10 .2012
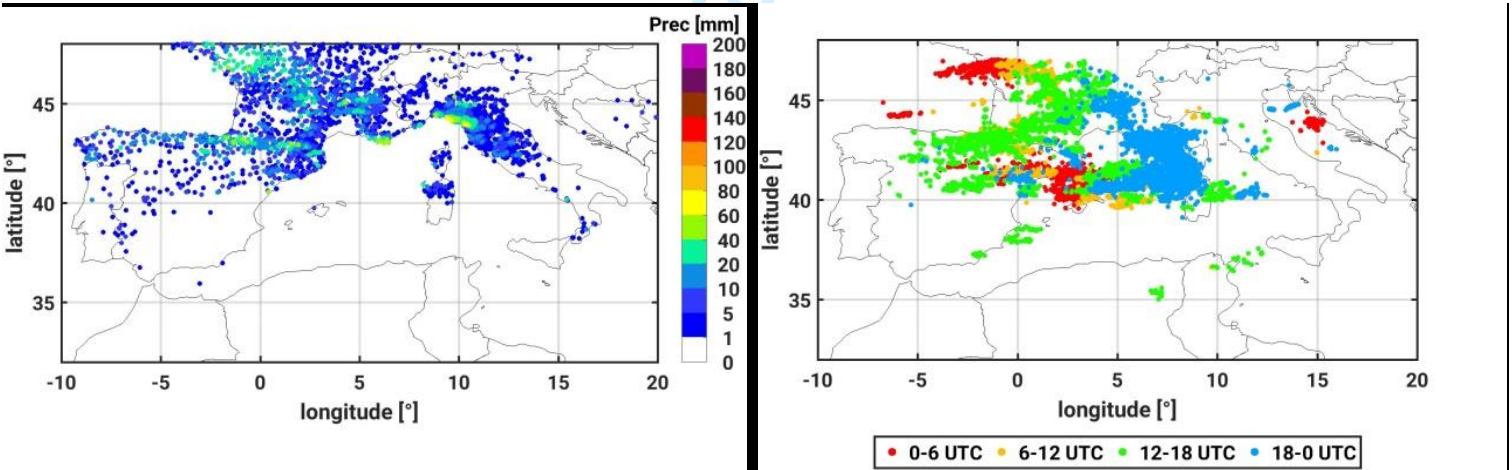

1077

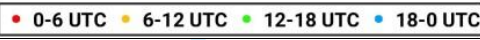

1078

1079

(c) 12.10 .2012
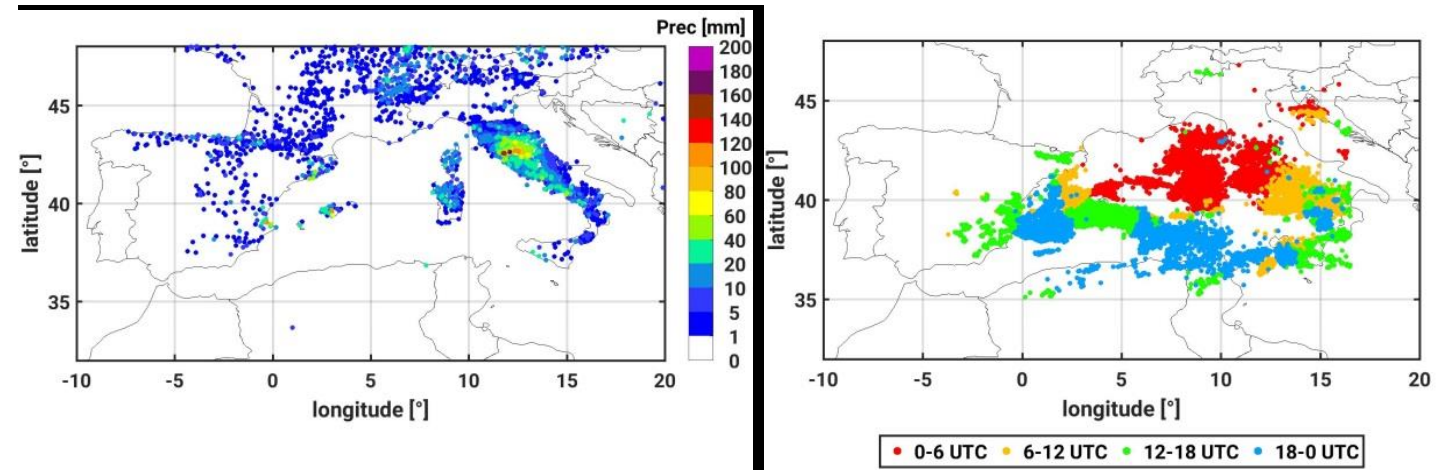

1080

$\bullet$ 0-6 UTC $~ 6-12$ UTC $\cdot 12-18$ UTC $\cdot$ 18-0 UTC 


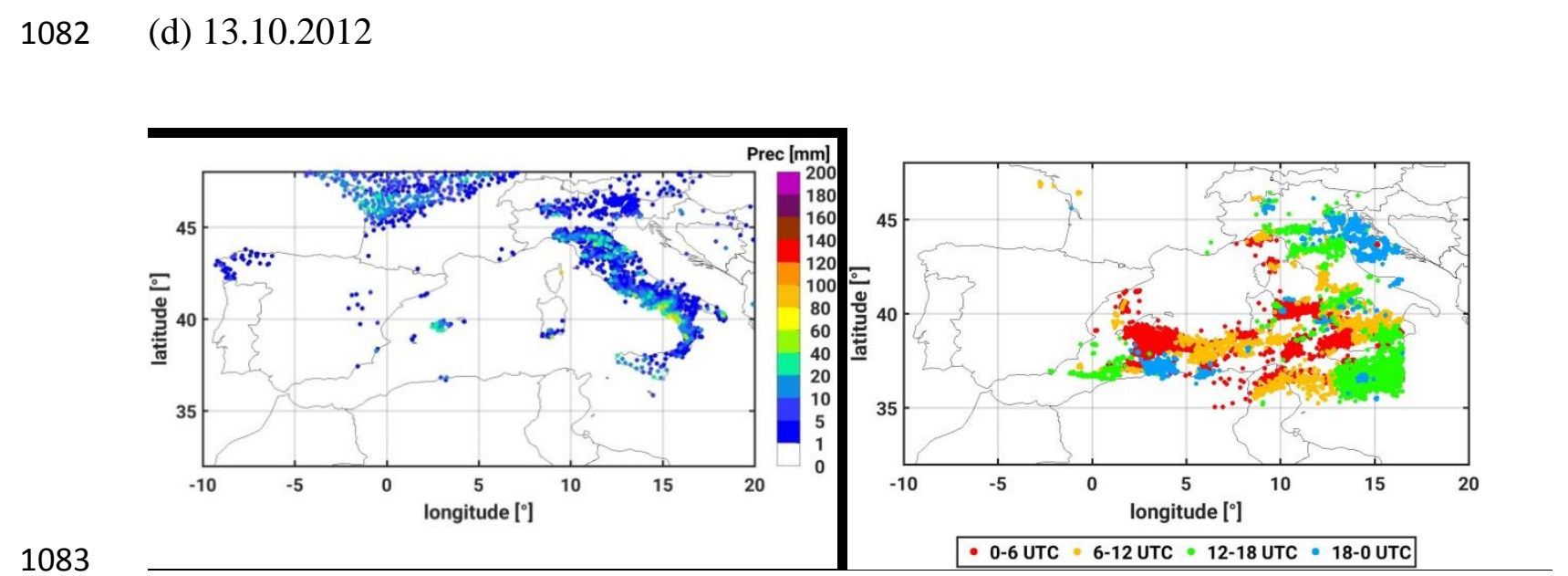

Figure 4: (a-d, left) Daily precipitation sums from 0600 UTC to 0600 UTC from $1 \mathrm{~h}$ rain 1085 gauge measurements and (right) EUCLID lightning observations (only available up to $16^{\circ} \mathrm{E}$ ). 1086 1087 1088 1089 1090 1091 1092 1093 1094 1095 1096 1097 


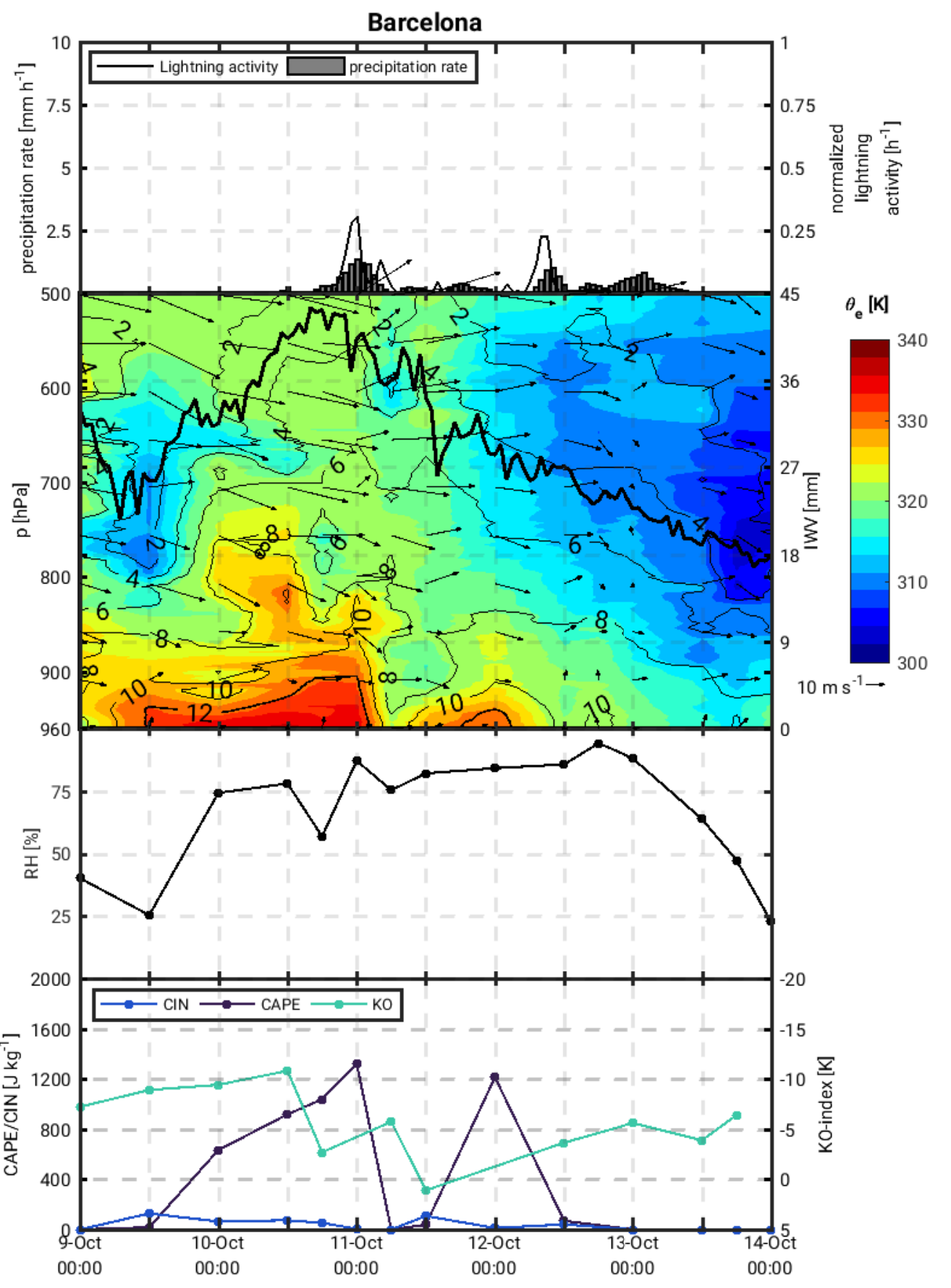


1103 (b)

1104

1105

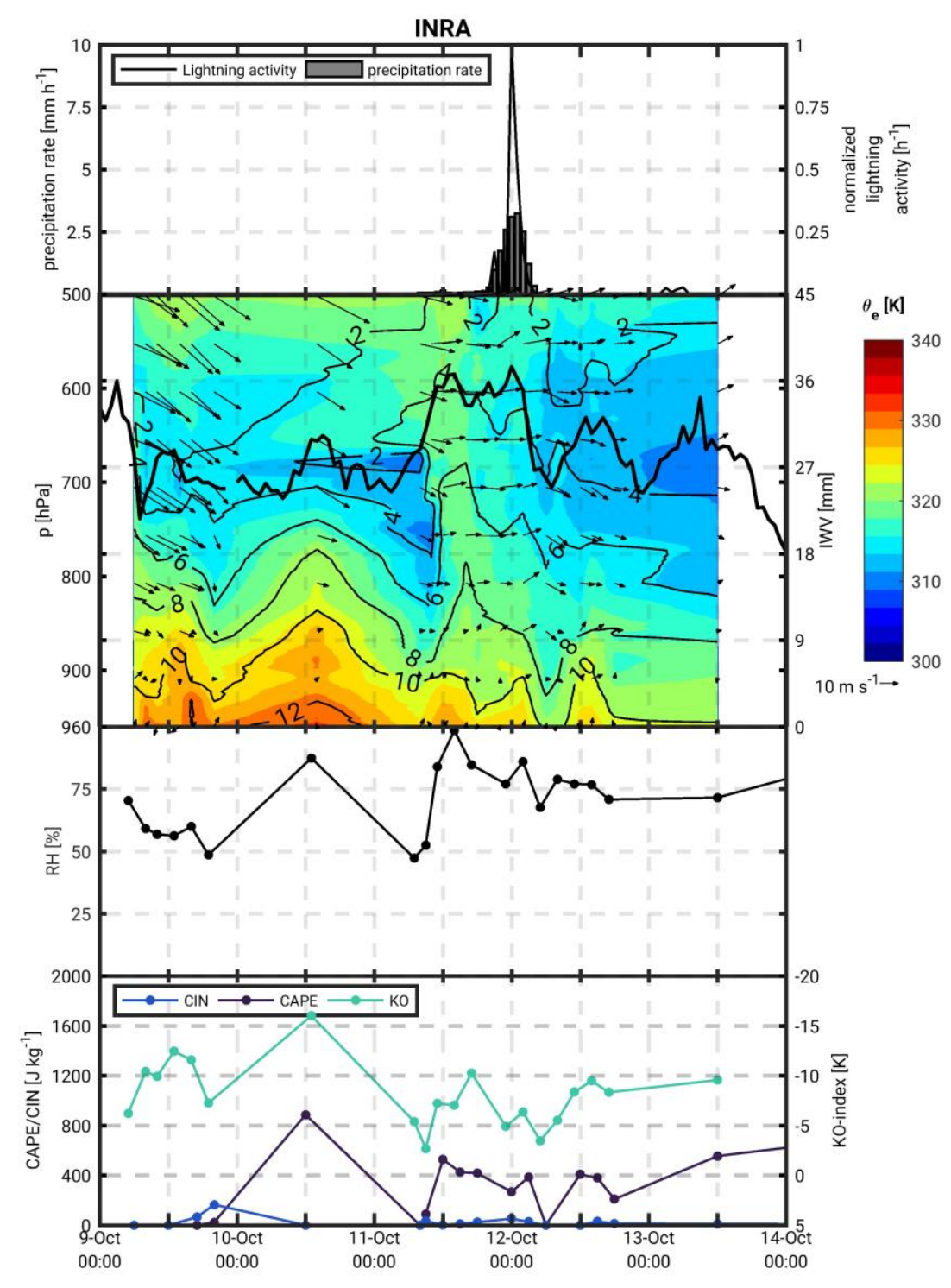


1112 (c)

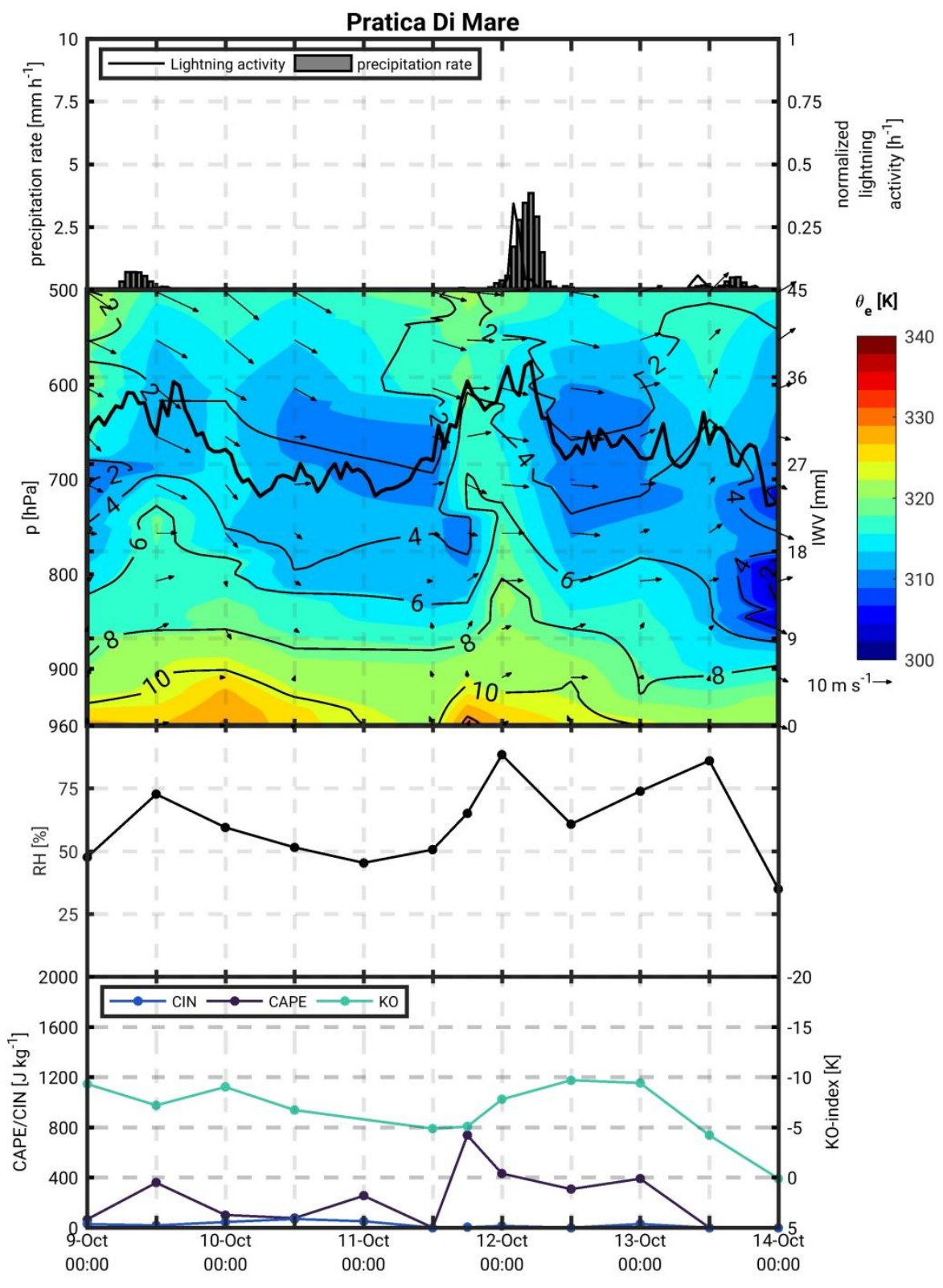

1113 
1119 (d)

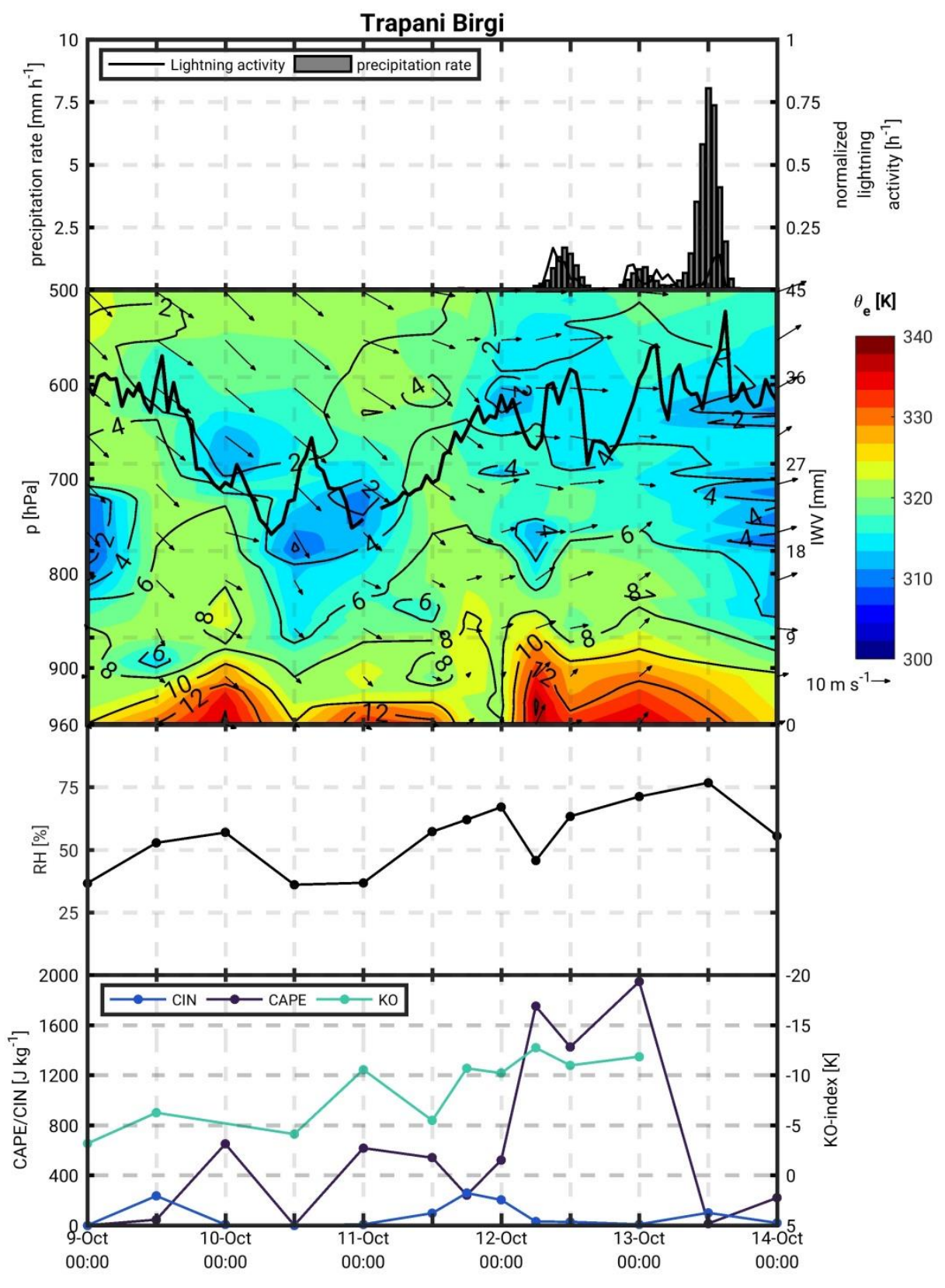


1125 Figure 5: Temporal evolution of (from top to bottom): Areal mean CMORPH hourly 1126 precipitation observations and EUCLID lightning; vertical cross-sections of equivalent 1127 potential temperature, specific humidity and horizontal wind (north pointing upwards) for 1128 selected stations using radiosounding data; IWV temporal evolution of the closest GPS station 1129 is included, mean relative humidity $(\mathrm{RH})$ averaged between 850 and $700 \mathrm{hPa}$ and temporal 1130 evolution of CAPE, CIN and KO-index calculated from corresponding radiosonde for: (a) 1131 Barcelona, (b) KIT-INRA, (c) Pratica Di Mare, (d) Trapani Birgi. Position of stations and 1132 selected areas are indicated in Figure 1. 
CAPE, IWV and $q$

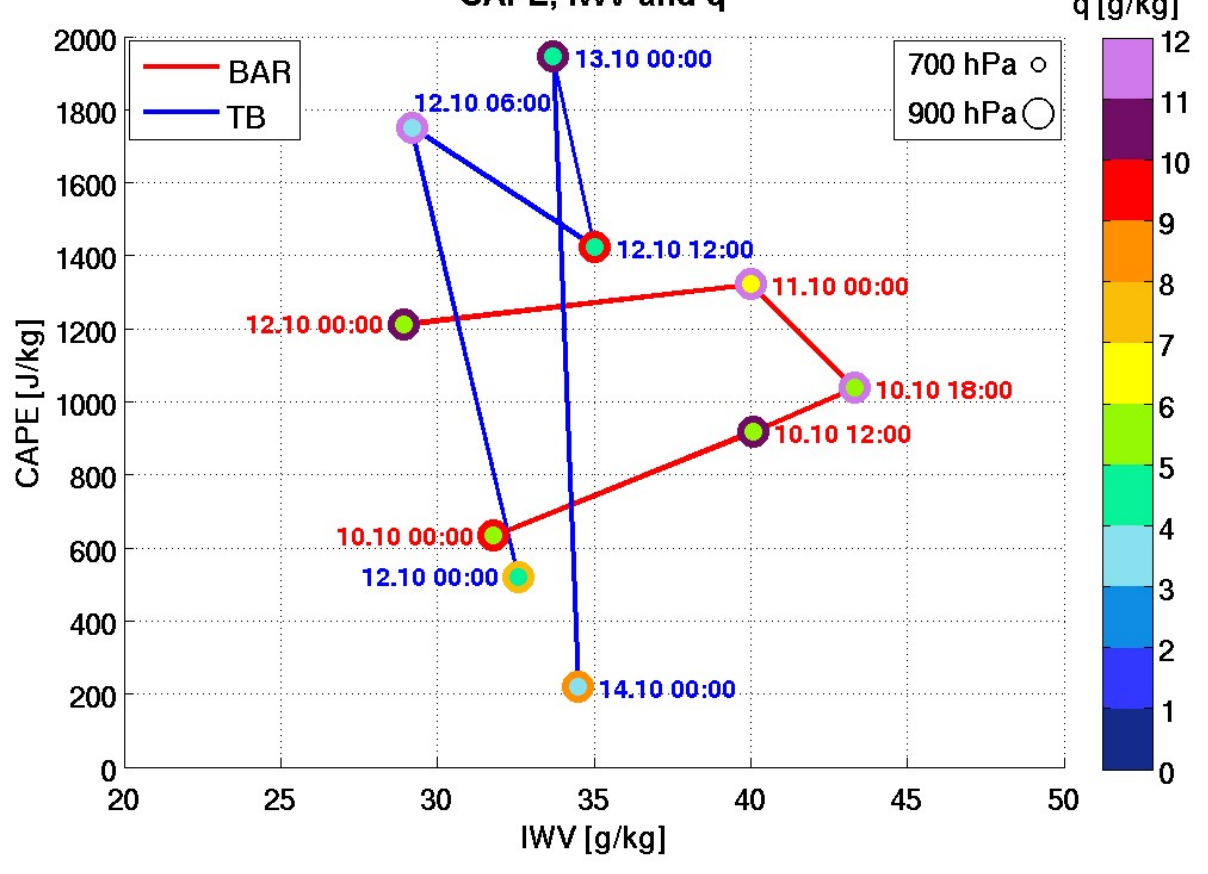

1142 Figure 6: Temporal evolution of CAPE in relation to IWV and specific humidity at 900 \pm 50 $1143 \mathrm{hPa}$ and $700 \pm 50 \mathrm{hPa}$ using the Barcelona (BAR/AREA1; max prec $\sim 50 \mathrm{~mm}^{-1} \mathrm{day}^{-1}$ at about 11 1144 October at 0000 UTC), and Trapani Birgi (TB/AREA4; max prec $200 \mathrm{~mm} \mathrm{day}^{-1}$ in the 1145 morning of the 13 October) radiosounding atmospheric profile information. As indicated in 1146 the legend, the inner circle indicates the $700 \mathrm{hPa}$ specific humidity values and the outer circle 1147 the $900 \mathrm{hPa}$ specific humidity values. 
1153

(a) 09.10 .2012

(b) 10.10 .2012
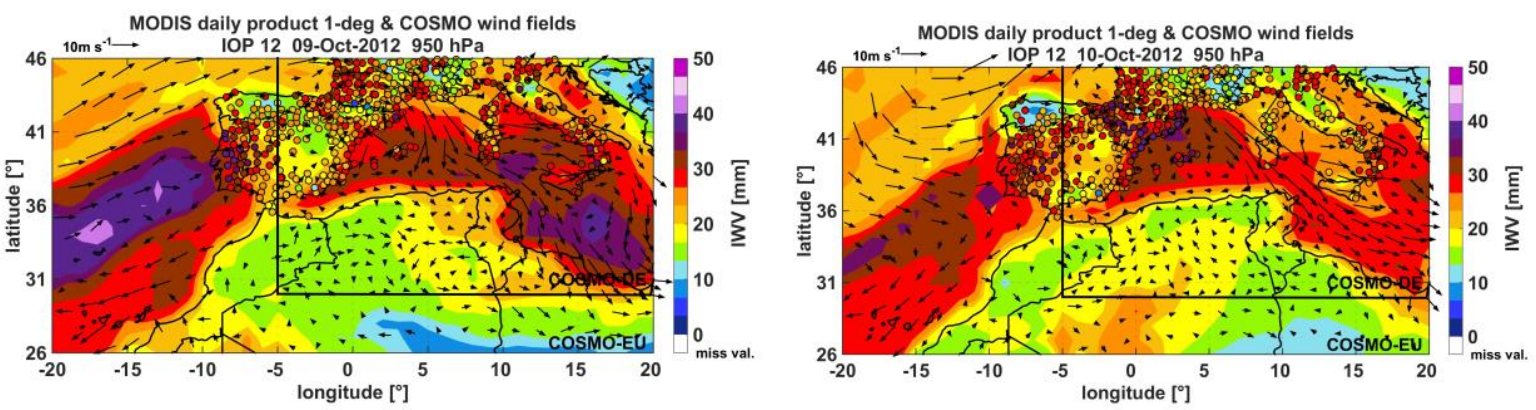

1154

1155

(c) 11.10 .2012

(d) 12.10 .2012
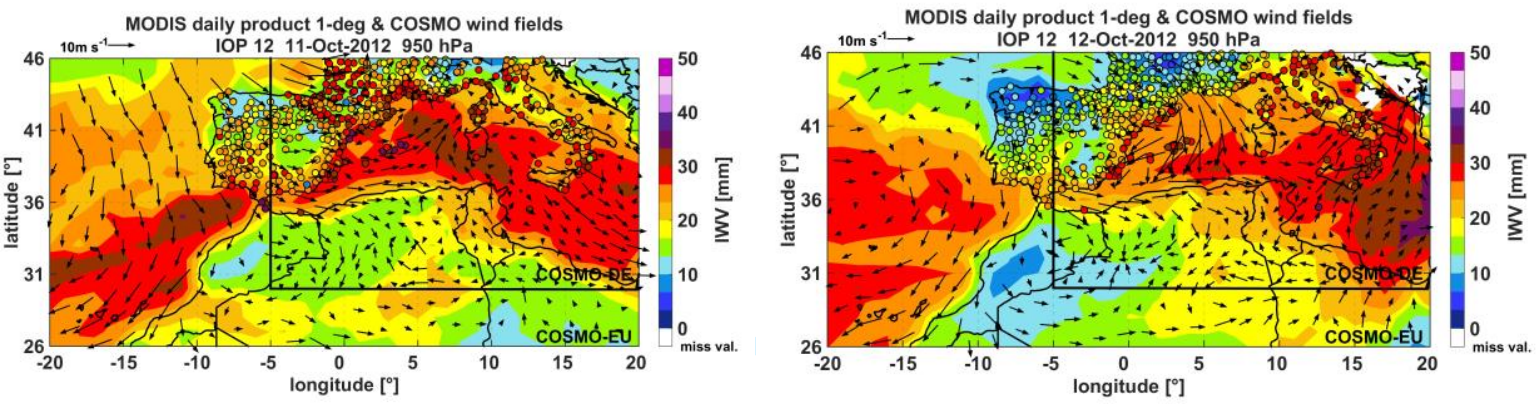

$1157 \quad$ (e) 13.10 .2012

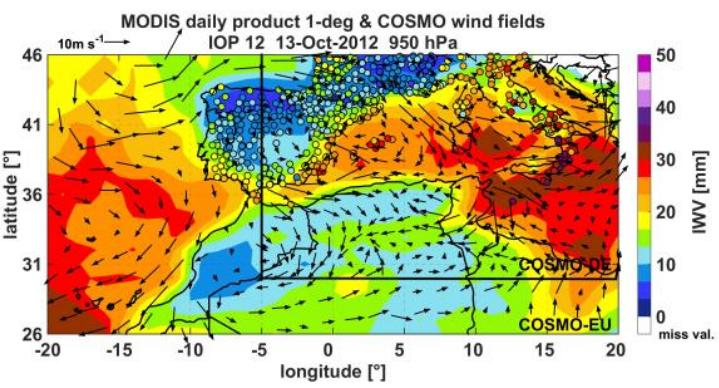

1158

1159

1160

Figure 7: Daily mean spatial distribution of total column Integrated Water Vapour (IWV)

1161 from MODIS (background) and GPS (circles) observations for (a) 09 October 2012, (b) 10

1162 October 2012, (c) 11 October 2012, (d) 12 October 2012 and (e) 13 October 2012. Simulated

1163 COSMO-7 km and COSMO-2.8km $950 \mathrm{hPa}$ winds at $1200 \mathrm{UTC}$ are superimposed. 

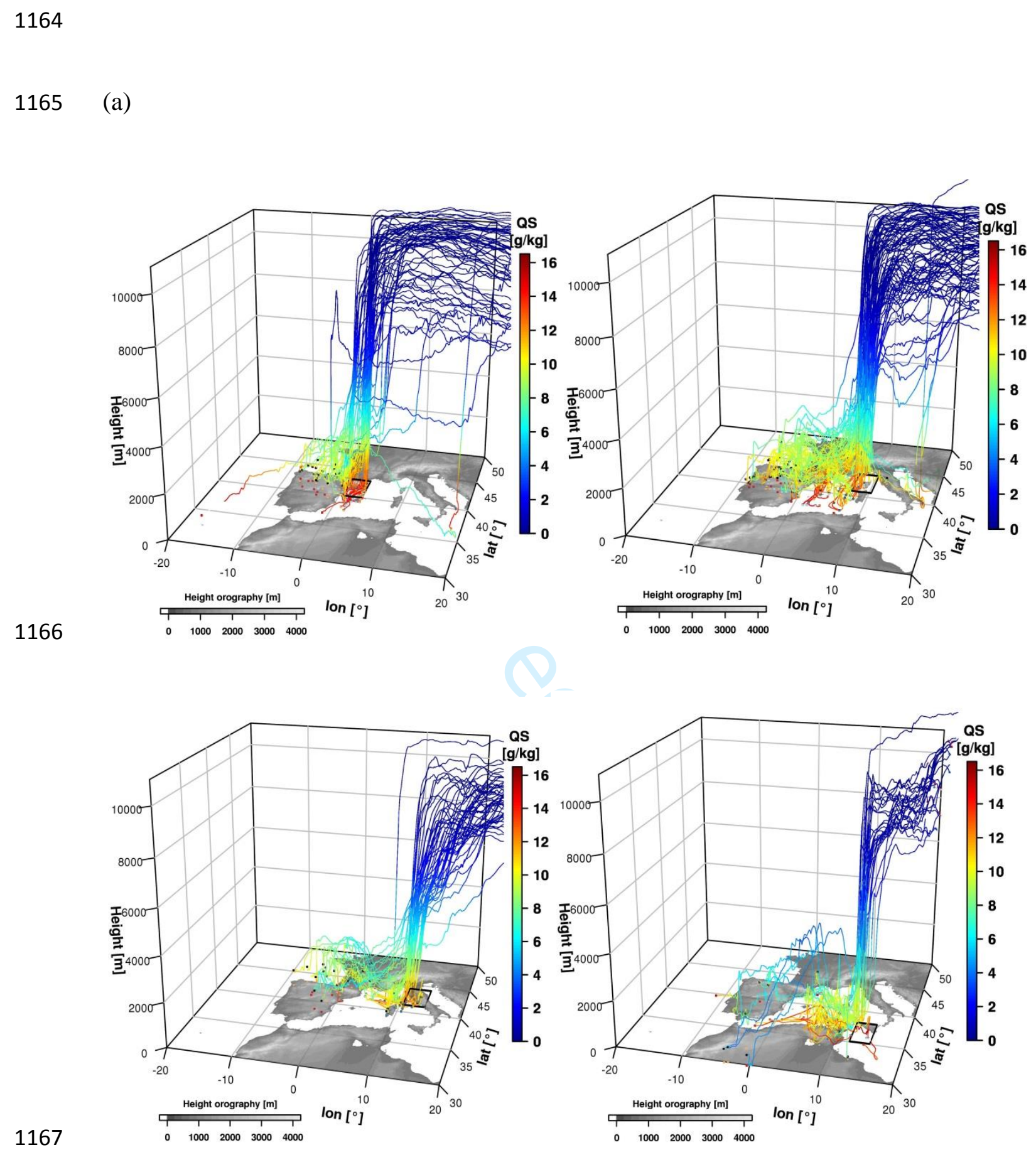
1173 (b)
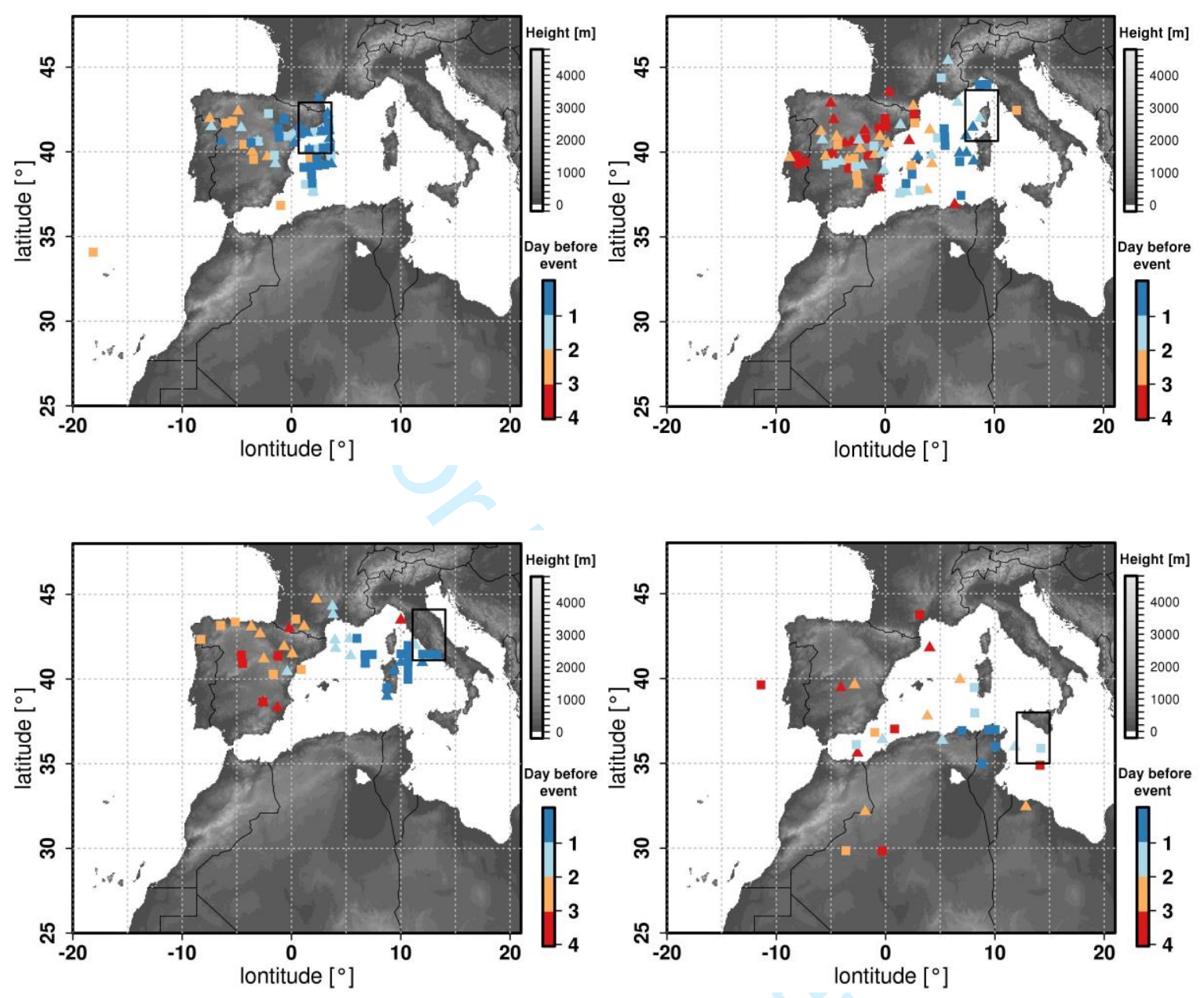

Figure 8: (a) Trajectory and (b) origin of air parcels contributing to the formation of the

1178 heavy precipitation systems in each of the affected areas (black boxes) as determined from the 1179 COSMO Lagrangian trajectories module. The orography of the region is depicted in whiteblack scale. In (a) the colour scale indicates the specific humidity along the air parcel 1181 trajectories. In (b) the symbols locate the origin of the air parcel trajectories and the colour 1182 scale indicates the number of simulated days prior to the precipitation event. The symbols 1183 themselves represent the starting time of trajectories (squares at 00UTC and the triangles at 1184 12UTC). 
1185

$1186 \quad$ (a)

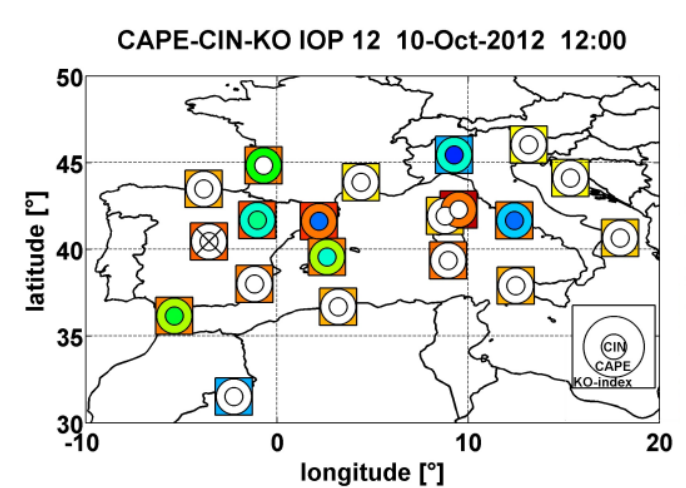

1187

1188

(c)

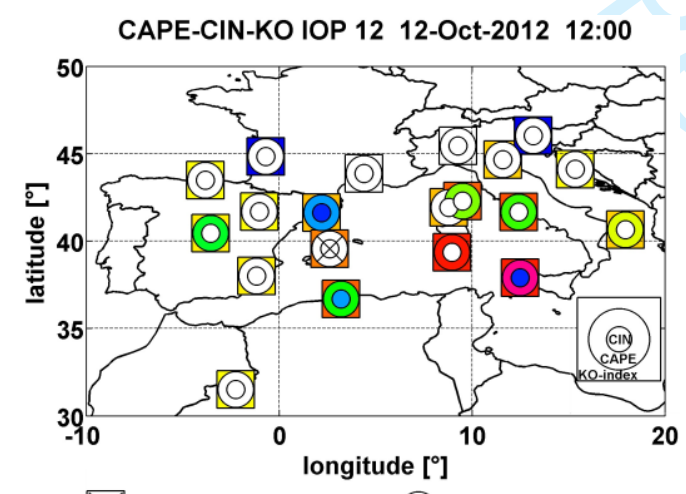

1189

$\bigotimes_{\text {miss. val. of Ko-index }}$

(Q) miss. val. of CAPE and CIN (b)

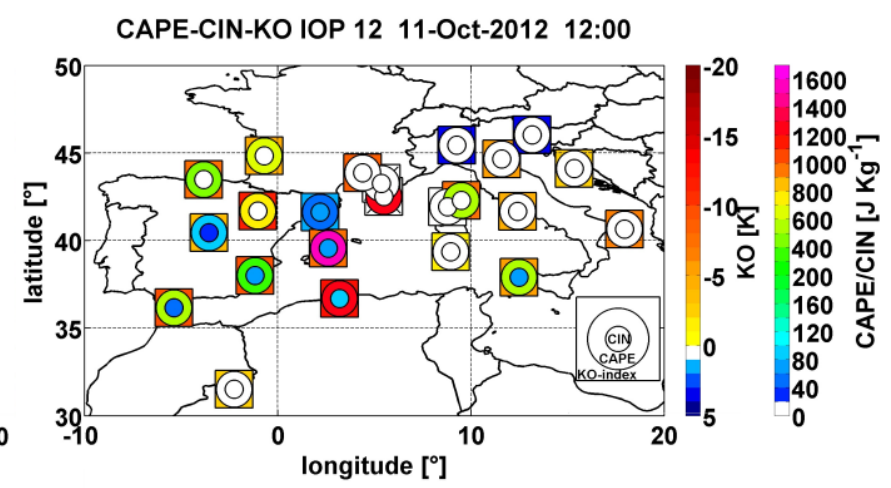

$\bigotimes$ miss. val. of KO-index $\$$ miss. val. of CAPE and CIN

(d)

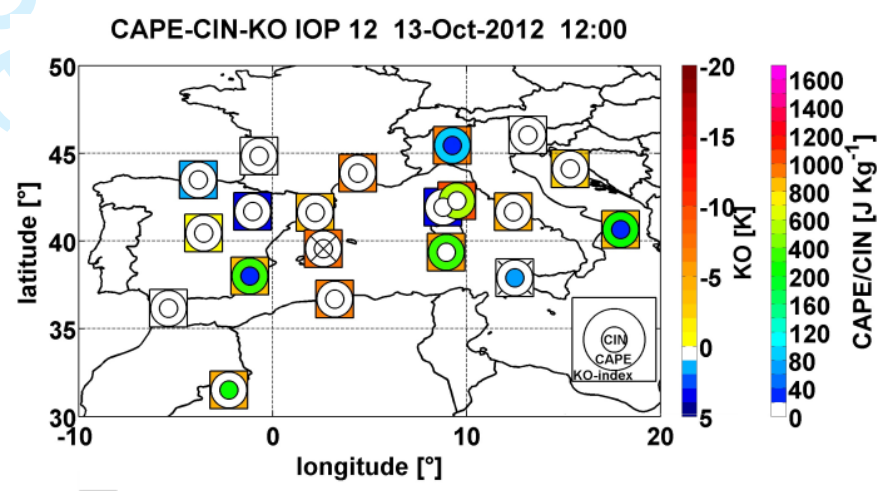

$\bigotimes$ miss. val. of KO-index $\quad$ (8) miss. val. of CAPE and CIN

1190

1191 Figure 9: Spatial distribution of CAPE, CIN and KO-index on the 10, 11, 12 and 13 October 11922012 at 1200 UTC. As indicated in the legend, the inner circle indicates CIN values, the outer 1193 circle represents the CAPE values, and the square reflects the KO-index values. 


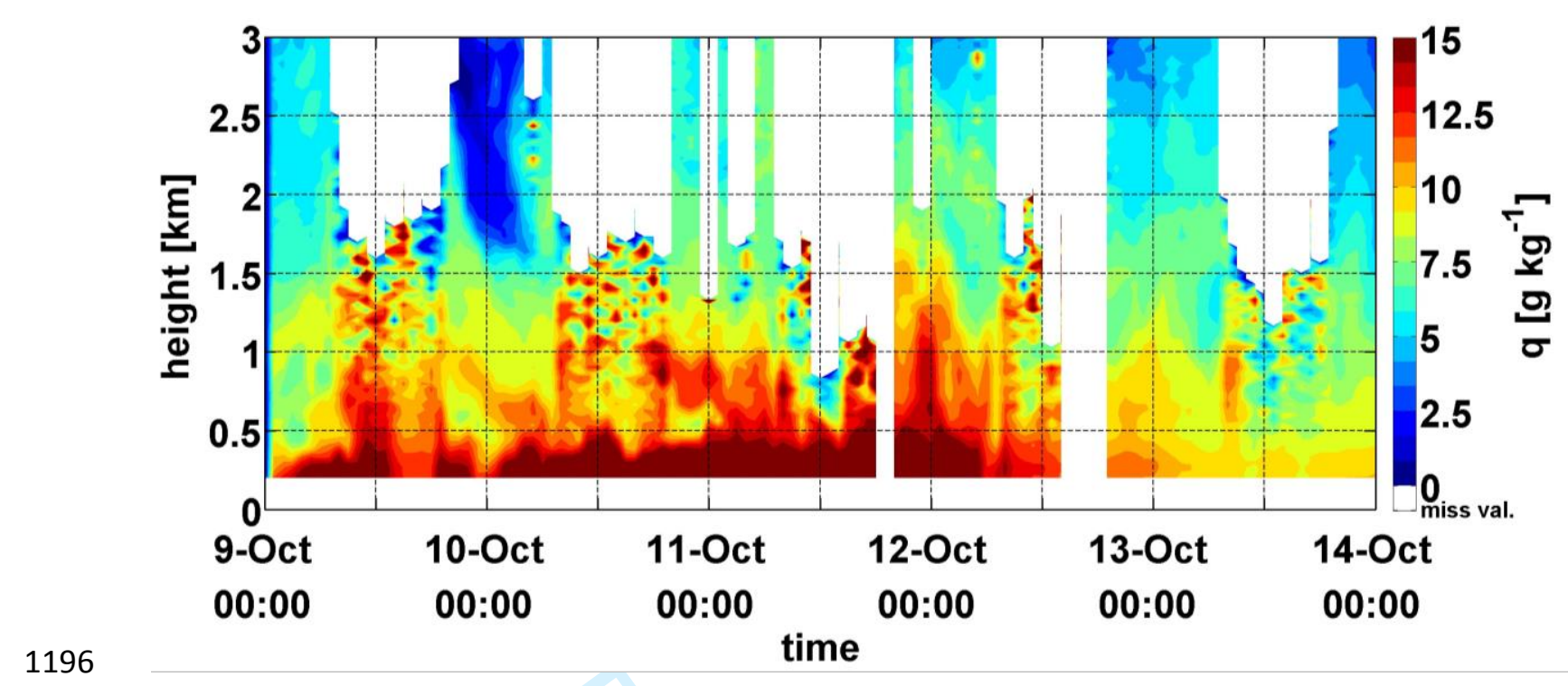

$1197 \quad(b)$

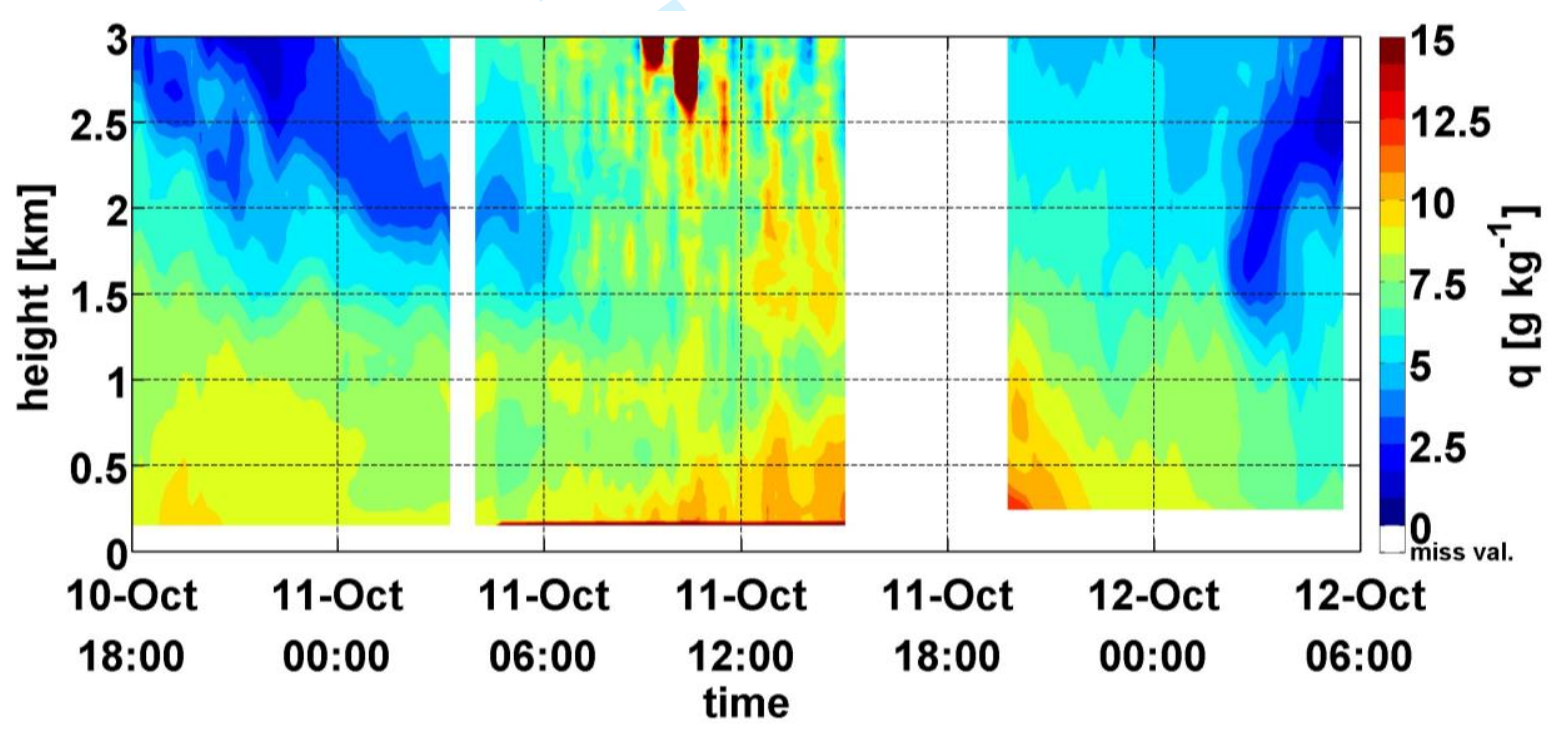

1200 Figure 10: (a) Water vapour mixing ratio from 9 to 14 October 2012 over Menorca (Balearic 1201 Islands) as measured by the Raman lidar WALI. (b) Water vapour mixing ratio from 10 to 12 1202 October 2012 over Candillargues (south France) as measured by the Raman lidar BASIL. 1203 Please note the different time scales. The data gaps are due to cloud cover or heavy rain. 
(a)
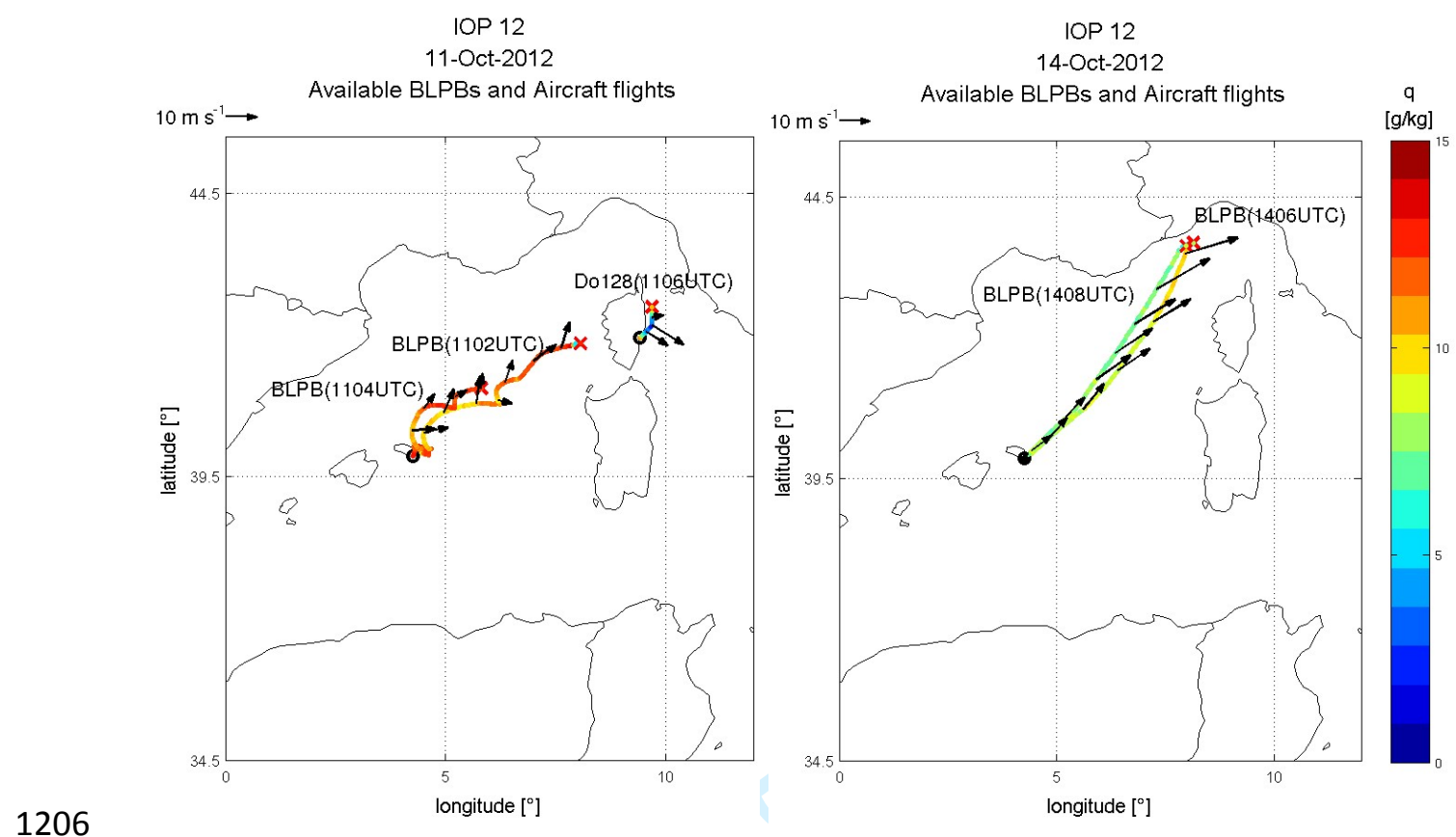

1207

(b1)

1208

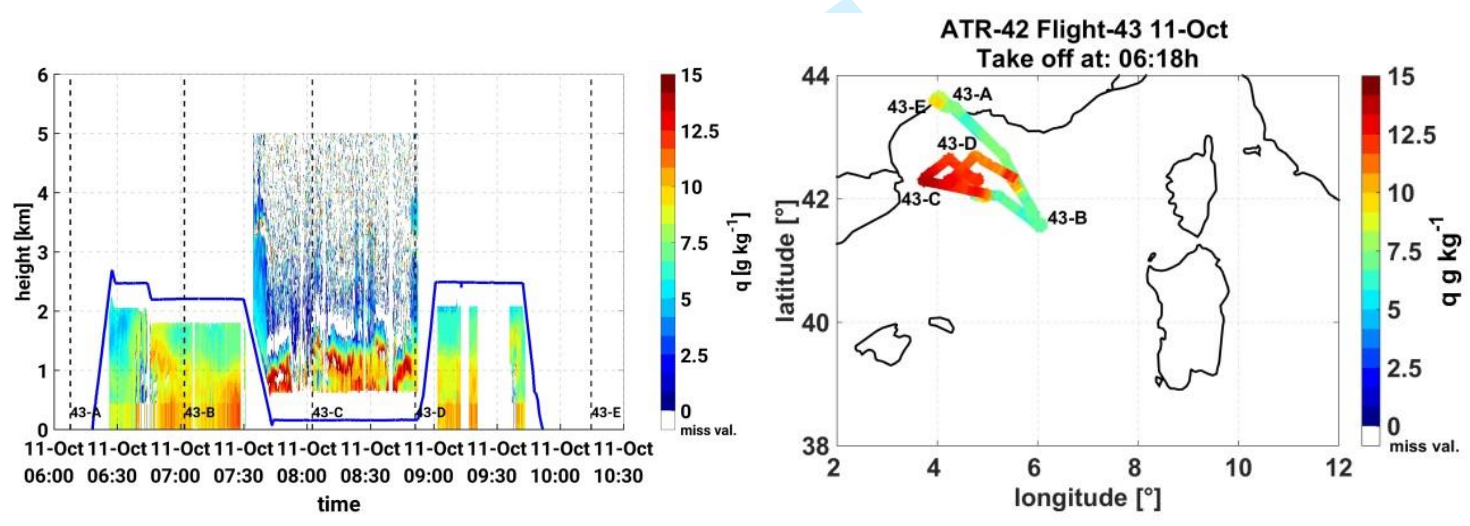

1209

1210

1211

1212

1213 

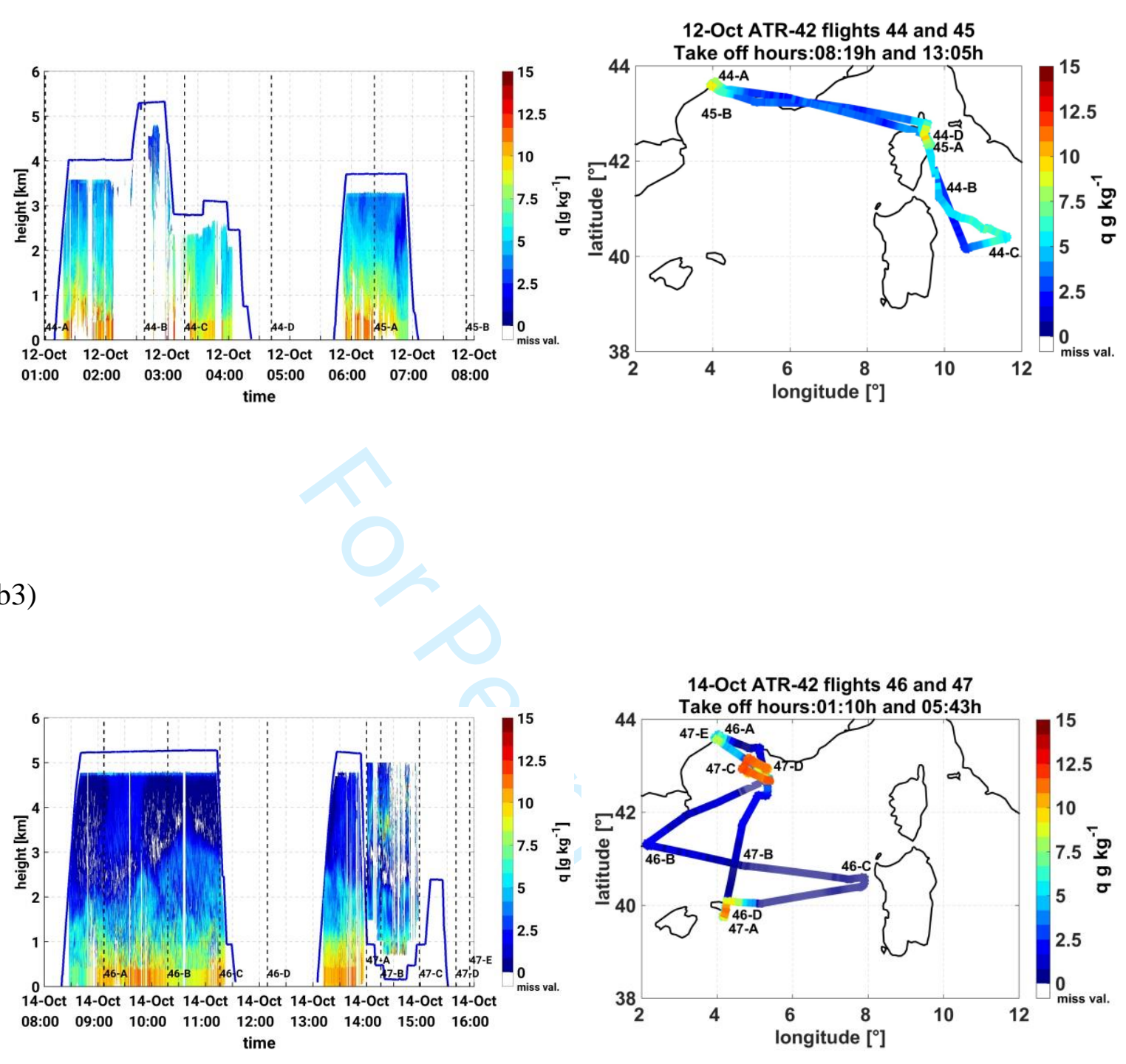

1219 Figure 11: (a) Boundary Layer Pressurized Ballons (BLPB) path depicting specific humidity 1220 and horizontal wind at about 500-700 m amsl on 11 October 2012 and 14 October 2012. DO1221128 specific humidity and wind observations in the lower PBL for the 11 October are also 1222 included. (b) Vertical-cross section of specific humidity measured by the LEANDRE 2 lidar 1223 on board of the ATR-42 aircraft, on the 11, 12 and 14 October 2012 for the indicated periods. 1224 Flight tracks and altitude are also indicated. 
1227 Tables

1228 Table 1: Complementary information on storms presented in Figure 3. The lifespan and 1229 maximum anvil surface were estimated based on information contained in the RTD product 1230 (accuracy is $\pm 15 \mathrm{~min}$ for the time estimates and $\pm 500 \mathrm{~km}^{2}$ for maximum anvil expansion). 1231 Maximum precipitation amounts are inferred from rain gauge measurements over land and 1232 CMORPH satellite derived precipitation observations over the sea. Synoptic forcing 1233 information is based on GFS model output and surface pressure charts (source 1234 www.wetter3.de). Near-surface observations are based on SYNOP wind observations.

\begin{tabular}{|c|c|c|c|c|}
\hline Storm & $\begin{array}{l}\text { Lifespan } \\
{[\mathrm{h}]}\end{array}$ & $\begin{array}{l}\text { Max. surface } \\
{\left[\mathrm{x10}^{3} \mathrm{~km}^{2}\right]}\end{array}$ & $\begin{array}{l}\text { Max. prec } \\
{[\mathrm{mm}]}\end{array}$ & Forcing \\
\hline $\mathbf{A}$ & 19.5 & 39 & $50 / 24 \mathrm{~h}$ & $\begin{array}{l}\text { Near-surface } \\
\text { convergence line }\end{array}$ \\
\hline B1 & 7 & 37 & $75 / 6 h$ & Near-surface \\
\hline B2 & 4.5 & 23 & $40 / 6 h$ & convergence line, \\
\hline $\begin{array}{l}\text { C } \\
\text { (merged } \\
\text { B1\&B2) }\end{array}$ & 4 & 130 & $50 / 24 h$ & $\begin{array}{l}\text { secondary trough, surface } \\
\text { cold front }\end{array}$ \\
\hline $\mathbf{D}$ & 8 & 93 & $150 / 6 \mathrm{~h}$ & $\begin{array}{l}\text { Near-surface } \\
\text { convergence line, } \\
\text { secondary trough, surface } \\
\text { cold front }\end{array}$ \\
\hline $\mathbf{M}$ & 18 & 140 & $150-200 / 6 h$ & $\begin{array}{l}\text { Near-surface } \\
\text { convergence line and } \\
\text { secondary trough }\end{array}$ \\
\hline
\end{tabular}




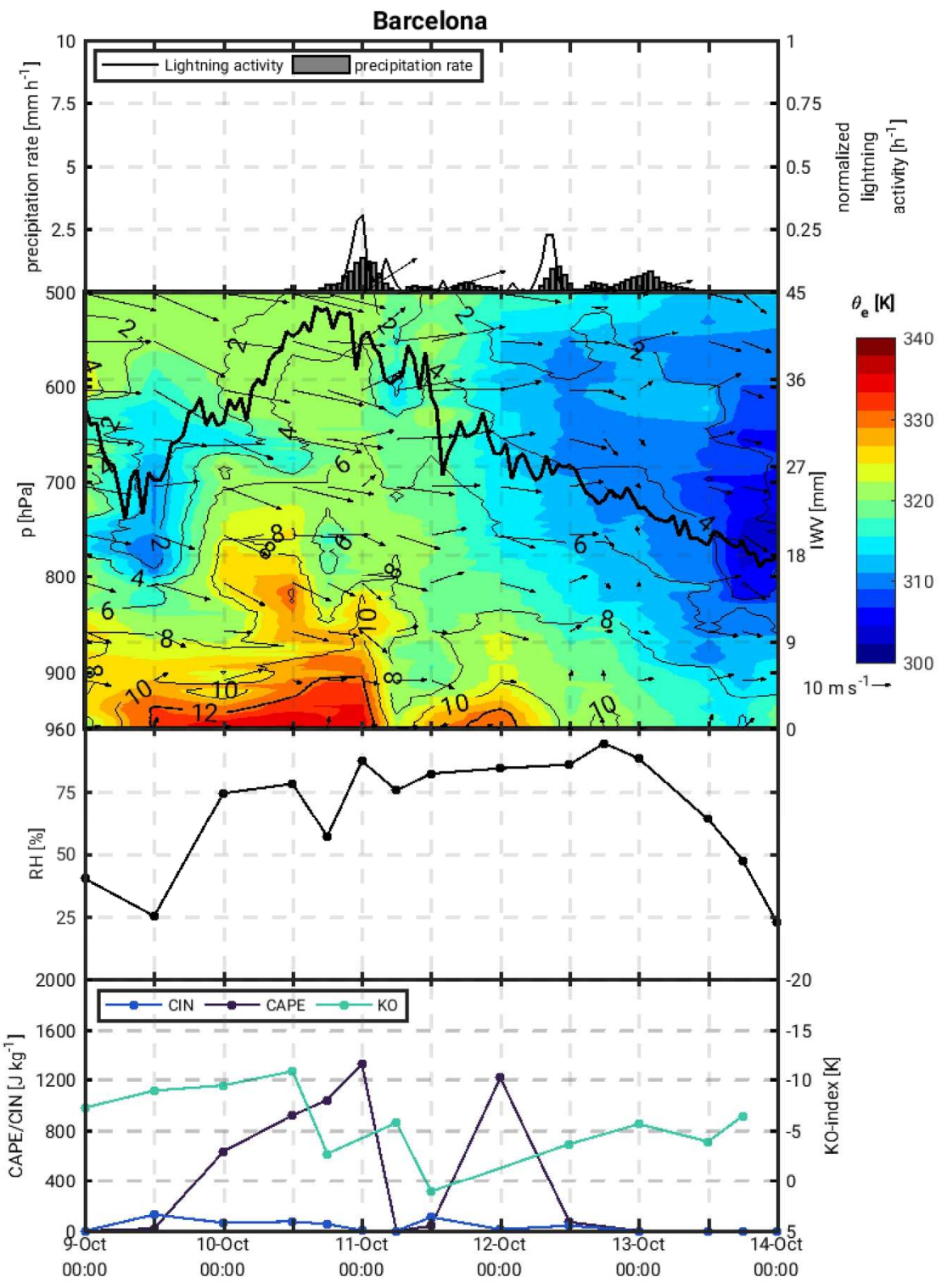

$185 \times 233 \mathrm{~mm}(300 \times 300$ DPI $)$ 


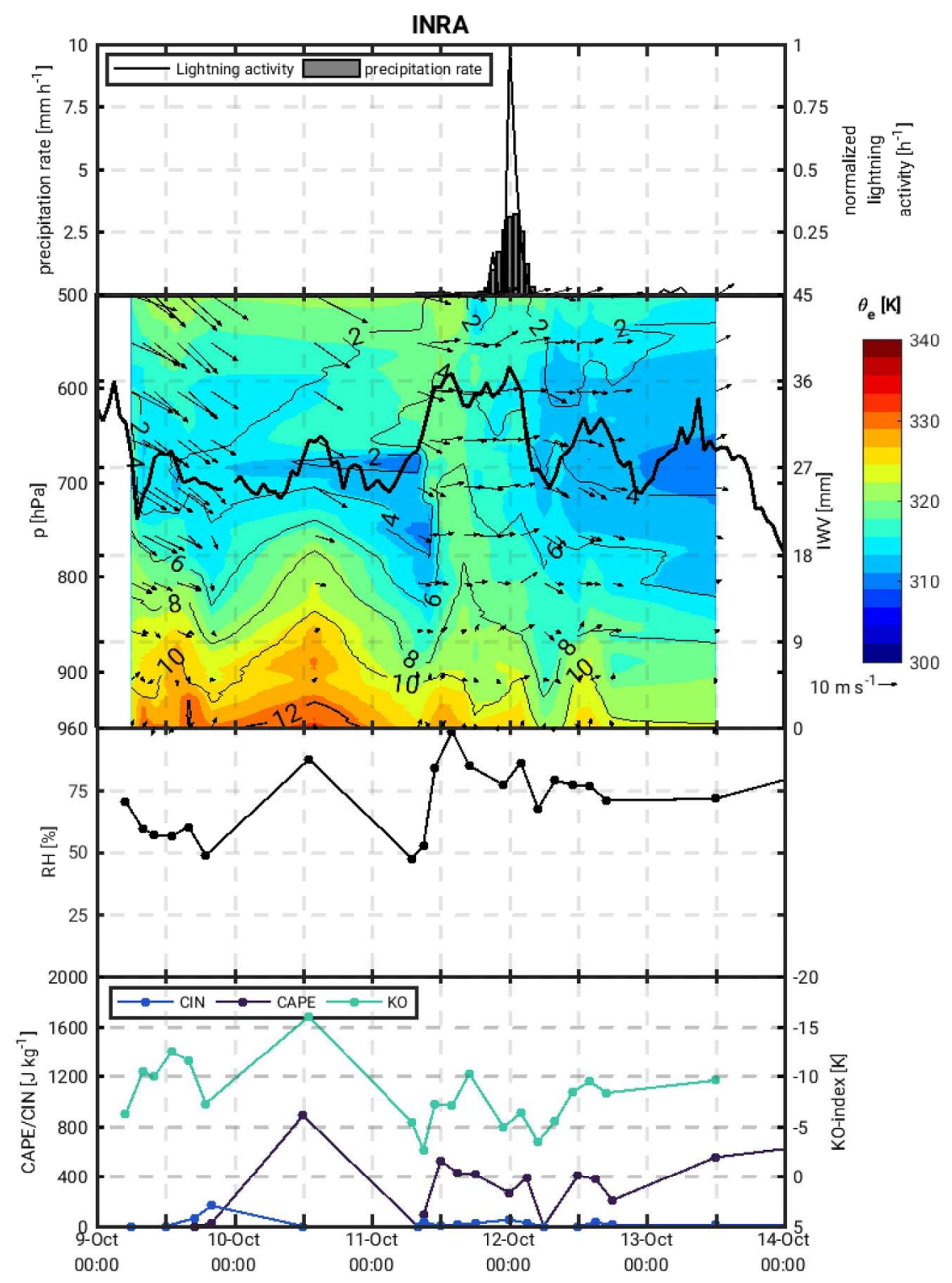

$185 \times 233 \mathrm{~mm}(300 \times 300$ DPI $)$ 


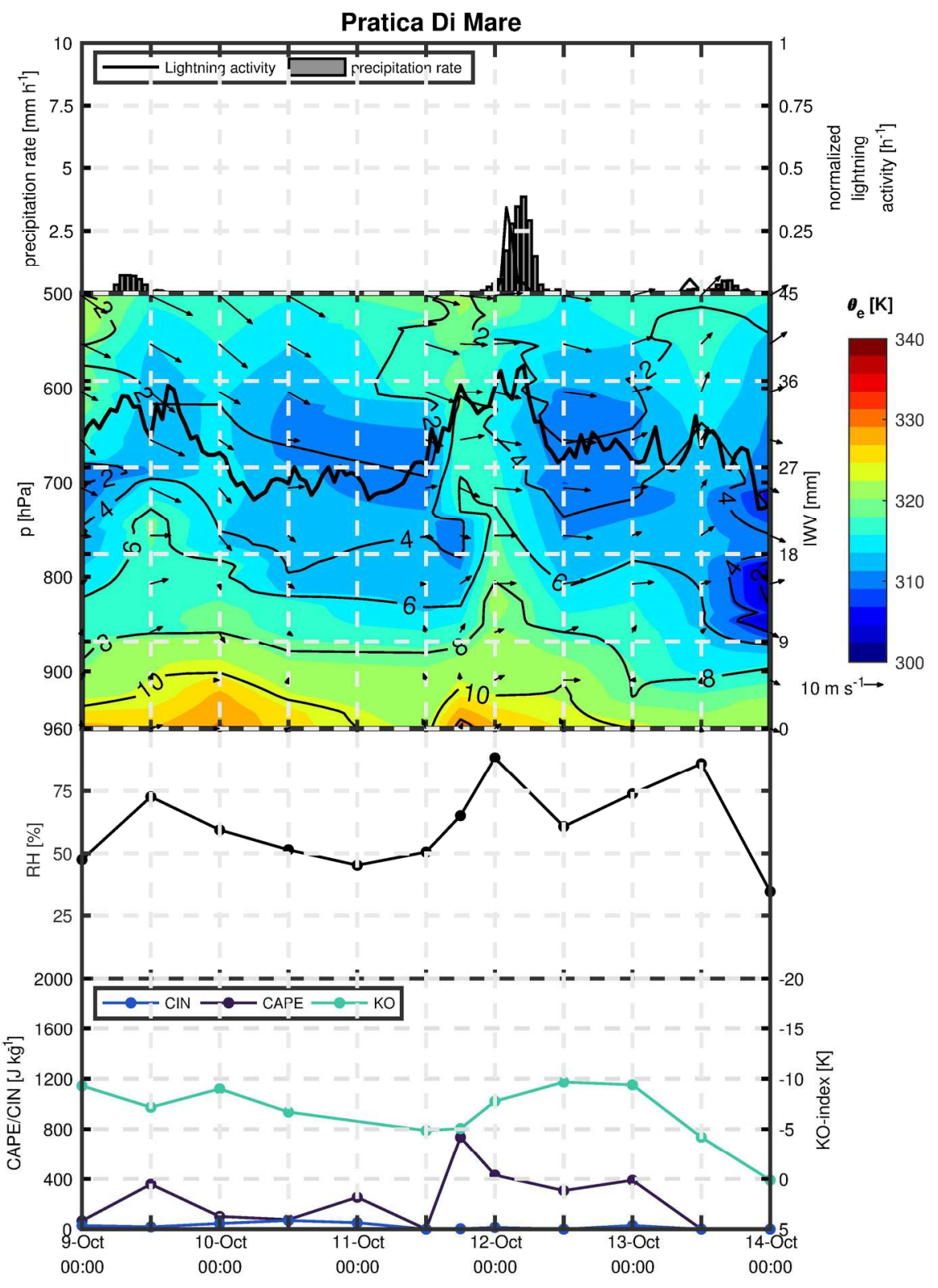

$177 \times 242 \mathrm{~mm}(300 \times 300$ DPI $)$ 


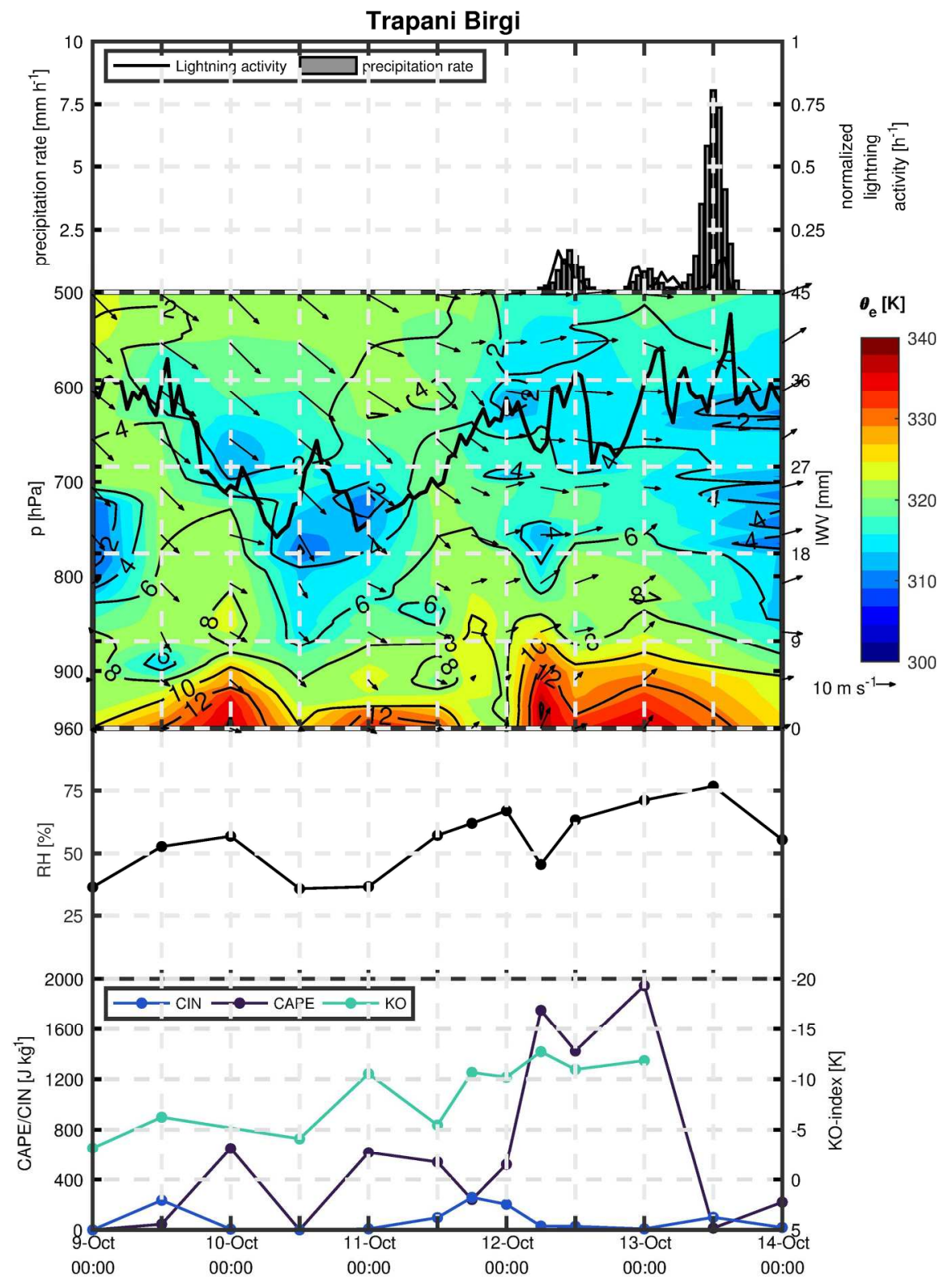

$177 \times 242 \mathrm{~mm}(300 \times 300$ DPI $)$ 